\title{
Biosynthesis of Silver and Gold Nanoparticles Using Aqueous Extract of Codonopsis pilosula Roots for Antibacterial and Catalytic Applications
}

\author{
Van-Dat Doan $\left(\mathbb{D},{ }^{1}\right.$ Bao-An Huynh, ${ }^{1}$ Thanh-Danh Nguyen $\left(\mathbb{D},{ }^{2}\right.$ Xuan-Thang Cao, ${ }^{1}$ \\ Van-Cuong Nguyen, ${ }^{1}$ Thi Lan-Huong Nguyen, ${ }^{3}$ Hoai Thuong Nguyen, ${ }^{4}$ \\ and Van Thuan Le ${ }^{5,6}$ \\ ${ }^{1}$ Faculty of Chemical Engineering, Industrial University of Ho Chi Minh City, Ho Chi Minh City, Vietnam \\ ${ }^{2}$ Institute of Chemical Technology, Vietnam Academy of Science and Technology, Ho Chi Minh City, Vietnam \\ ${ }^{3}$ Institute of Biotechnology and Food Technology, Industrial university of Ho Chi Minh City, Ho Chi Minh City, Vietnam \\ ${ }^{4}$ Faculty of Electrical Engineering Technology, Industrial University of Ho Chi Minh City, Ho Chi Minh City, Vietnam \\ ${ }^{5}$ Center for Advanced Chemistry, Institute of Research and Development, Duy Tan University, Da Nang City 550000, Vietnam \\ ${ }^{6}$ The Faculty of Environmental and Chemical Engineering, Duy Tan University, Da Nang City 550000, Vietnam
}

Correspondence should be addressed to Van Thuan Le; levanthuan3@duytan.edu.vn

Received 8 March 2020; Revised 11 May 2020; Accepted 28 May 2020; Published 24 June 2020

Academic Editor: Ashok K. Sundramoorthy

Copyright (C) 2020 Van-Dat Doan et al. This is an open access article distributed under the Creative Commons Attribution License, which permits unrestricted use, distribution, and reproduction in any medium, provided the original work is properly cited.

In this study, biogenic silver nanoparticles (AgNPs) and gold nanoparticles (AuNPs) were synthesized by a green approach using an aqueous extract from Codonopsis pilosula (CP) roots as a reducing and stabilizing agent. The formation of CP-AgNPs and CPAuNPs was confirmed and optimized by UV-Vis spectroscopy. The CP-AgNPs and CP-AuNPs obtained under optimum conditions of metal ion concentration, reaction temperature, and reaction time were characterized by high-resolution transition electron microscopy (HR-TEM), selected area electron diffraction (SAED) analysis, field-emission scan electron microscopy (FE-SEM), powder X-ray diffraction (XRD) analysis, Fourier transform infrared (FTIR) spectroscopy, dispersive X-ray spectroscopy (EDX), and dynamic light scattering (DLS) method. It has been found that the biosynthesized CP-AgNPs and CPAuNPs were formed in spherical shape with an average size of $10 \pm 2.5 \mathrm{~nm}$ and $20 \pm 3.2 \mathrm{~nm}$, respectively. The biosynthesized metallic nanoparticles exhibited selective bacterial activity against three bacterial strains including two Gram-positive bacteria of Bacillus subtilis and Staphylococcus aureus and one Gram-negative bacteria of Escherichia coli. Meanwhile, there was no antibacterial activity detected toward Gram-negative Salmonella enteritidis. CP-AgNPs and CP-AuNPs also manifested an excellent catalytic performance in the reduction of 1,4-dinitrobenzene, 2-nitrophenol, 3-nitrophenol, and 4-nitrophenol.

\section{Introduction}

In recent years, there has been a growing interest in the synthesis of metal nanoparticles (MNPs) such as silver nanoparticles (AgNPs) and gold nanoparticles (AuNPs) due to their useful properties for applications in different areas of medicine, biology, catalysis, and antibacterial [1-4]. Along with the rapid development of nanotechnology, several promising approaches were utilized to synthesize AgNPs and AuNPs [5-7]. Owing to the simplicity and rapid operation, chemical reduction methods using commercial chemicals such as hydrazine [8], sodium borohydride [9], ascorbic acid [10], and ethylene glycol [11] are widely applied to convert gold and silver ions into metals at nanoscale. However, these methods have a major drawback related to the toxicity originated from the excess amount of the used chemicals that can affect the quality of nanoproducts. Recently, green approaches have been preferred to use. Among them, the way of using extracts of plants as reducing agents is quite popular, especially in developing countries, with several advantages such as high efficiency and potential for practical applications [12-14]. As reported in literatures [15-18], 
different parts of plants such as leaves, stems, roots, tubers, and flowers that contain a high amount of bioactive molecules with water-soluble polyol components responsible in reduction and stabilization of biogenic AgNPs and AuNPs were deployed already for the synthesis.

The biogenic MNPs are well known as effective catalysts for the complete degradation of toxic effluents and hydrogenation of derivatives based on nitroaromatic compounds. Among them, 4-nitrophenol (4-NP), 3-nitrophenol (3-NP), 2-nitrophenol (2-NP), and 1,4-dinitrobenzene (1,4-DNB) are dangerous pollutants contained in industrial wastewater that is discharged mainly from petrochemical refining, pesticides, fertilizer production, and dyes-related manufacturing activities [19]. The catalytic reduction of the mentioned above nitroaromatic compounds using AgNPs and AuNPs in the role of catalysts has been widely studied [20]. Furthermore, it is determined that the biosynthesized AgNPs and AuNPs at nanosize ranged from about 6 up to $100 \mathrm{~nm}$ also demonstrated a strong antibacterial activity against various microorganisms as Escherichia coli (E. coli), Staphylococcus aureus (S. aureus), Bacillus subtilis (B. subtilis), Salmonella typhimurium (S. typhimurium) [21, 22], Streptococcus pyogenes [23], Pantoea agglomerans, Staphylococcus sp., Klebsiella sp., and Rahnella sp. bacteria [24].

Codonopsis pilosula (Franch.) Nannf. (CP) belonging to Campanulaceae family is a perennial herb grows naturally in mountains of Vietnam, China, and India with bellflower and wire stem. Commonly, the extracts of CP roots were used as a traditional medicine for health promotion, prevention, and treatment of many diseases [25]. The main chemical constituents of CP roots include phytosteroids, sesquiterpenes, triterpenes, alkaloids, alkyl alcohol glycosides, phenylpropanoid glycosides, polyacetylene glycosides, and polysaccharides that could be an excellent source for synthesizing AgNPs and AuNPs [26, 27].

In this study, the aqueous extract of CP roots was used as a reducing and stabilizing agent simultaneously for the biosynthesis of AgNPs and AuNPs. The biosynthesized MNPs were studied for antimicrobial activity toward four bacterial strains including two Gram-positive bacteria (B. subtilis and S. aureus) and two Gram-negative bacteria (Salmonella Enteritidis (S. Enteritidis) and E. Coli), and for catalytic degradation of $1,4-\mathrm{DNB}, 2-\mathrm{NP}, 3-\mathrm{NP}$, and $4 \mathrm{NP}$ in aqueous medium.

\section{Materials and Methods}

2.1. Materials and Chemicals. All chemicals used were of analytical grade and utilized without further purification. Silver nitrate $\left(\mathrm{AgNO}_{3}\right)$ and hydrogen tetrachloroaurate(III) hydrate $\left(\mathrm{HAuCl}_{4} \cdot 3 \mathrm{H}_{2} \mathrm{O}\right)$ were purchased from Acros (Belgium). Sodium tetrahydridoborate $\left(\mathrm{NaBH}_{4}\right), 1$,4-dinitrobenzene $\left(\mathrm{C}_{6} \mathrm{H}_{4} \mathrm{~N}_{2} \mathrm{O}_{4}\right)$, 2-nitrophenol $\left(\mathrm{C}_{6} \mathrm{H}_{5} \mathrm{NO}_{3}\right)$, 3-nitrophenol $\left(\mathrm{C}_{6} \mathrm{H}_{5} \mathrm{NO}_{3}\right)$, and 4-nitrophenol $\left(\mathrm{C}_{6} \mathrm{H}_{5} \mathrm{NO}_{3}\right)$ were supplied by Merck (India). CP roots were collected from mountainous province Gialai, Vietnam. Four bacterial strains including two Gram-positive bacteria (B. subtilis and S. aureus) and two Gram-negative bacteria (S. Enteritidis and E. Coli) were provided by the Department of Biotechnology, Institute of
Food and Biotechnology, Industrial University of Ho Chi Minh City, Vietnam.

2.2. Preparation of CP Aqueous Extract. The dried CP roots were finely ground up powder using an electronic blender. The CP root powder $(5 \mathrm{~g})$ was boiled in distilled water $(300 \mathrm{~mL})$ with reflux for $1 \mathrm{~h}$. The obtained mixture was filtered with Whatman filter paper No.1 to remove the solid, and the extract was stored in a refrigerator at $4-10^{\circ} \mathrm{C}$ for further experiments.

2.3. Synthesis of Biogenic AuNPs and AgNPs. Synthesis of biogenic AuNPs and AgNPs was performed with $\mathrm{HAuCl}_{4}$, $\mathrm{AgNO}_{3}$ solutions, and aqueous CP extract. Briefly, $10 \mathrm{~mL}$ of $\mathrm{CP}$ extract was mixed with $10 \mathrm{~mL}$ of metallic ion solutions under vigorous stirring in the dark. The change in the solution color after reactions complete acts as a visual sign for the success of the synthesis process. Factors that affect the synthesis process, such as concentration $(0.5-2 \mathrm{mmol} / \mathrm{L})$, temperature $\left(60-100^{\circ} \mathrm{C}\right)$, and time $(15-180 \mathrm{~min})$ were also investigated to determine the optimal conditions using UVVis measurements on an Evolution $300 \mathrm{UV}-\mathrm{V}$ is spectrophotometer with characterized maximum absorption peaks of AgNPs and AuNPs at around 420 and $540 \mathrm{~nm}$, respectively. The obtained MNPs under optimal conditions were centrifuged, dried, and then used to study their physico-chemical characteristics and antimicrobial and catalytic activities. The procedure for the biosynthesis of CP-AgNPs and CPAuNPs with their applications can be illustrated in Figure 1.

\subsection{Characterization of Biogenic AgNPs and AuNPs} Nanoparticles. Fourier transform infrared spectroscopy (FTIR) in the range of $4000-500 \mathrm{~cm}^{-1}$ on a Bruker Tensor 27 (Germany) was applied to detect covalent bonds of possible functional groups presented in the dried CP extract and powdered MNPs. Powder X-ray diffraction (XRD) analysis on a Shimadzu $6100 \mathrm{X}$-ray diffractometer (Japan) operating at the voltage of $40 \mathrm{kV}$, the current of $30 \mathrm{~mA}$ with $\mathrm{CuK} \alpha$ radiation at the wavelength of $1.5406 \mathrm{~nm}$, scanning speed of $0.05^{\circ} \mathrm{s}$ and step size of $0.02^{\circ}$ in the range $2 \theta$ from $10^{\circ}$ to $80^{\circ}$ was used to determine the crystalline structure and composition of MNPs. The morphology of the MNPs in colloidal solution was determined by transmission electron microscope (TEM) and high-resolution transmission electron microscope (HR-TEM) on a JEOL JEM-2100 (Japan) at an accelerated voltage of 120 and $200 \mathrm{kV}$, respectively. The selected area electron diffraction pattern (SAED) of the nanoparticles was also recorded. Morphology of biosynthesized MNPs in the aggregation form after centrifugation was also examined by field-emission scanning electron microscopy (FE-SEM) on a Hitachi S-4800 HI-9057-0006 (Japan) at an accelerating voltage of $10 \mathrm{kV}$. A Horiba EMAX Energy EX-400 analyzer (Japan) was used to perform energy dispersive X-ray spectroscopy (EDX) for the determination of the chemical elemental composition of the powder nanoparticles. Finally, the dynamic diameter of MNPs in colloidal solution was examined by a Horiba SZ-100 (Japan) using dynamic light scattering (DLS) technology. 


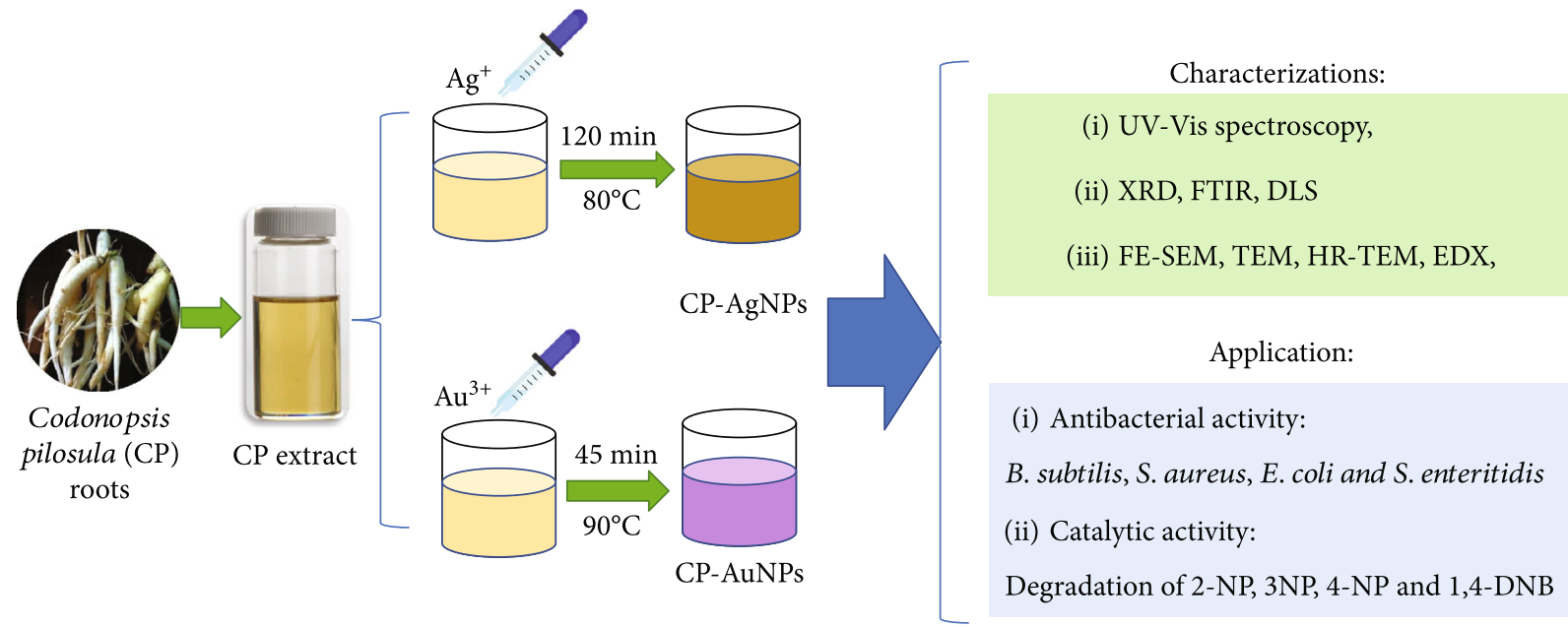

FIgURE 1: Schematic illustration for biosynthesis of CP-AgNPs and CP-AuNPs with their applications.

2.5. Antibacterial Activity. Antibacterial performance of the CP-AgNPs and CP-AuNPs in the form of optimized stable colloidal solution was studied by the agar disk diffusion method. The standard antibiotic ampicillin $(0.1 \mu \mathrm{g} / \mathrm{mL})$ was used as a positive control, while the aqueous CP-extract was used as a negative control. The used concentrations of MNPs were of $80,40,20,10,5 \mathrm{ppm}$ for CP-AgNPs, and $120,60,30,15,7.5 \mathrm{ppm}$ for CP-AuNPs. In the study, four bacterial strains including two Gram-positive bacteria $(B$. subtilis and $S$. aureus) and two Gram-negative bacteria ( $S$. Enteritidis and E. Coli) were applied to evaluate the antibacterial activity of the biosynthesized CP-AgNPs and CP-AuNPs. Briefly, aliquots $(50 \mu \mathrm{L})$ of CP-AgNPs and CP-AuNPs suspension were put into $6 \mathrm{~mm}$-diameter paper disks on Petri plates with the bacterial culture of brainheart infusion $\left(100 \mu \mathrm{L}, 10^{6} \mathrm{CFU} / \mathrm{mL}\right)$ by Mueller Hinton agar. The plates were kept at $37^{\circ} \mathrm{C}$ for $24 \mathrm{~h}$, and the antibacterial activity was determined via the inhibition zone diameter of tested bacteria.

2.6. Catalytic Activity of $C P-A g N P s$ and $C P$-AuNPs. It has been reported that AgNPs and AuNPs exhibit strong catalytic activity for the complete hydrogenation of toxic nitrophenolic compounds to unharmful substances of respective aminophenols $[28,29]$. The catalytic performance of CPAgNPs and CP-AuNPs was investigated via reduction reaction of contaminated organic substances $(1,4-\mathrm{DNB}, 2-\mathrm{NP}$, 3-NP, and 4-NP) using $\mathrm{NaBH}_{4}$ solution as reducing agent in a cuvette at room temperature. The pollutants $(2.5 \mathrm{~mL}$ of $0.1 \mathrm{mmol} / \mathrm{L}$ ) was mixed with the excess amount of $\mathrm{NaBH}_{4}$ $(0.5 \mathrm{~mL}$ of $0.1 \mathrm{~mol} / \mathrm{L})$ and $\mathrm{CP}-\mathrm{AgNPs}$ and CP-AuNPs $(3 \mathrm{mg})$ added then. After the reaction completed, MNPs were recovered by centrifugation, washed thoroughly with ethanol for reuse. The catalytic performance and kinetics were evaluated using UV-Vis spectroscopy at the wavelength of 380 , 410,390 , and $400 \mathrm{~nm}$ for $2-\mathrm{NP}, 3-\mathrm{NP}, 4-\mathrm{NP}$, and 1,4-DNB, respectively. In the context, the amount of $\mathrm{NaBH}_{4}$ was used far beyond the concentration of pollutants, so the concentra- tion of $\mathrm{NaBH}_{4}$ could be considered as a constant during the reaction. In this regard, the reaction could be pseudo-firstorder one which the kinetics described by the linear equation $\ln (A t)=-\mathrm{kt}+\ln (A o)$ [30], where $k$ is the rate constant, $t$ is the reaction time, $A t$ and $A o$ are the concentrations of pollutants at the time $t$ and initial concentration, respectively. The rate constant $k$ is determined from the slope of the straight line using linear regression of $\ln (A t)$ over the reaction time $t$. All catalytic and antibacterial experiments were performed in triplicate to confirm the reproducibility of the results and data are presented as mean and standard deviation.

\section{Results and Discussions}

3.1. Optimization of CP-AgNPs and CP-AuNPs Synthesis. The optimization procedure is extremely necessary to ensure the stability of any preparation process in general, as well as the quality of MNPs obtained under optimum conditions using aqueous extract of plants as reducing and capping agents in particular [31]. In this study, the significant synthesis conditions including the concentration of metal ions, reaction temperature, and reaction time were optimized through UV-Vis measurements based on the surface plasmon resonance phenomenon in MNPs [32].

The optimum concentrations of metal ions were investigated by adjusting the respective concentrations of the $\mathrm{HAuCl}_{4}$ and $\mathrm{AgNO}_{3}$ solutions in the range of 0.5-1.5 mmol/L for $\mathrm{Au}^{3+}$ and $0.5-2 \mathrm{mmol} / \mathrm{L}$ for $\mathrm{Ag}^{+}$, while the reaction temperature and reaction time were kept constant at $80^{\circ} \mathrm{C}$ and $60 \mathrm{~min}$, respectively (Figures $2(\mathrm{a})$ and $2\left(\mathrm{a}^{\prime}\right)$ ). The results show that the concentration of metal ions strongly affects the formation of MNPs, avoiding the use of the excess amount of expensive precious metals. In fact, in small concentration range, the increase in metal ion concentration led to the higher UV-Vis absorbance. In the high concentration range, MNPs have been partially coagulated, resulting in a decrease in its UV-Vis absorbance. It has been found that the 

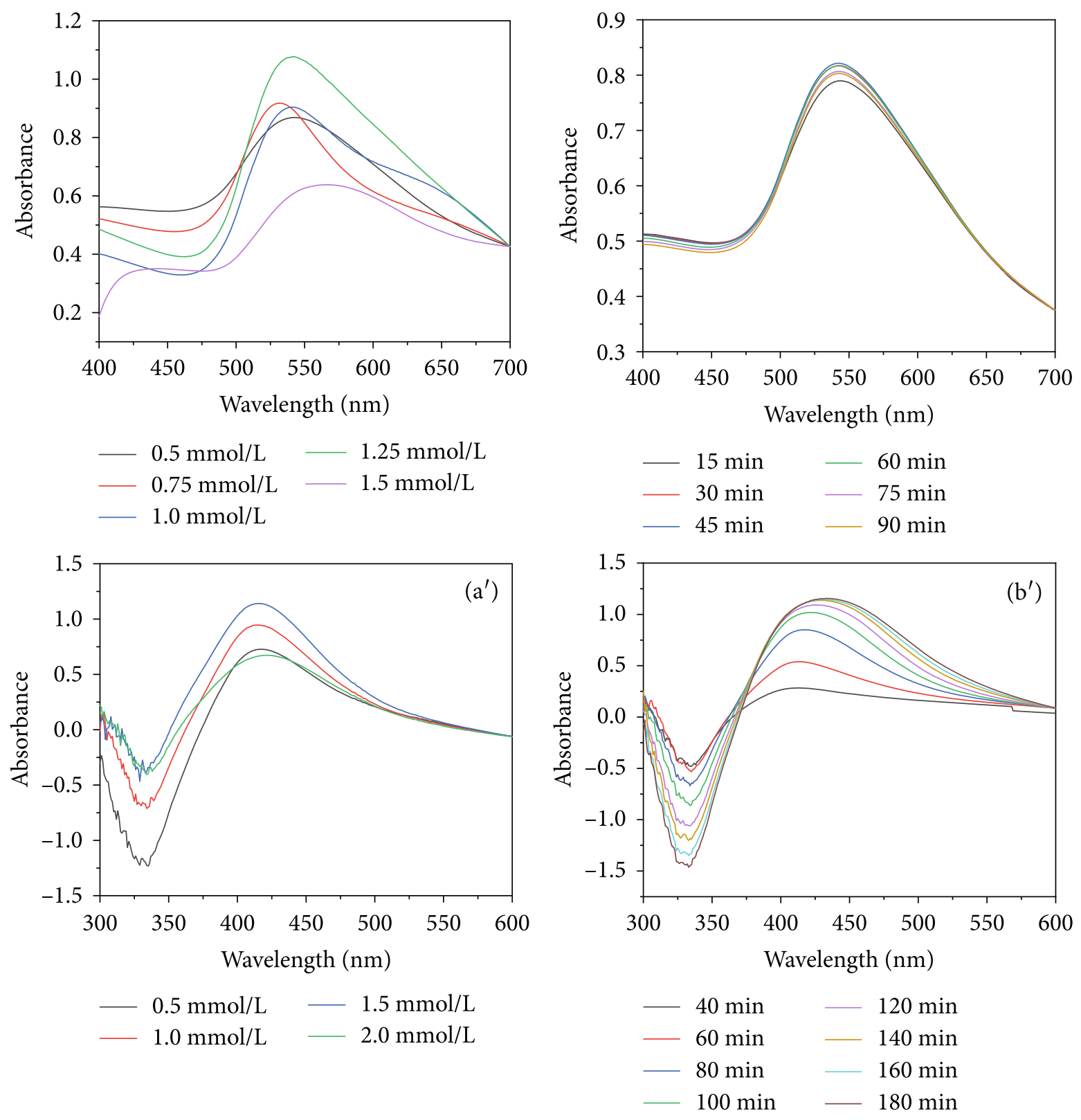
$-0.5 \mathrm{mmol} / \mathrm{L} \quad-1.5 \mathrm{mmol} / \mathrm{L}$
$-1.0 \mathrm{mmol} / \mathrm{L} \longrightarrow 2.0 \mathrm{mmol} / \mathrm{L}$

(a)

(b)

Figure 2: Continued. 

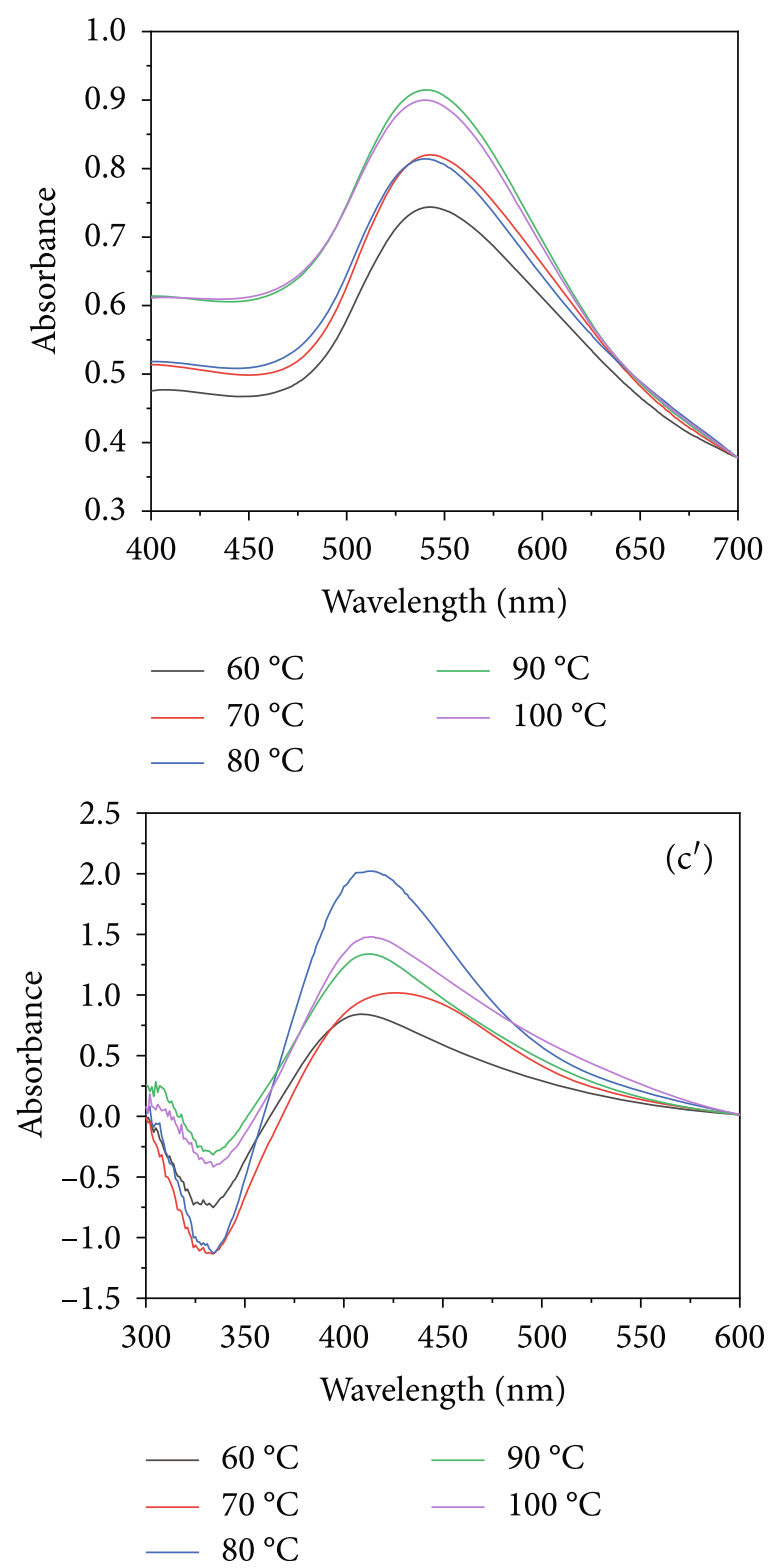

(c)

Figure 2: UV-Vis spectra of CP-AuNPs (a, b, c) and CP-AgNPs (a', b', c') suspensions: effects of concentration (a, a'), reaction time (b, b'), and reaction temperature $\left(c, c^{\prime}\right)$.

appropriate concentrations of $\mathrm{HAuCl}_{4}$ and $\mathrm{AgNO}_{3}$ necessary to form stable CP-AuNPs and CP-AgNPs with maximum yield are $1.25 \mathrm{mmol} / \mathrm{L}$ and $1.5 \mathrm{mmol} / \mathrm{L}$, respectively.

To find the suitable time for the formation of MNPs, the synthesis mixture $(2.5 \mathrm{~mL})$ was taken out to perform UV-Vis measurement for every 15 min toward CP-AuNPs and every 20 min toward CP-AgNPs while fixing the two other parameters $\left(80^{\circ} \mathrm{C}, 1.25 \mathrm{mmol} / \mathrm{L}\right.$ of $\mathrm{Au}^{3+}$, and $1.5 \mathrm{mmol} / \mathrm{L}$ of $\left.\mathrm{Ag}^{+}\right)$. As seen in Figures 2(b) and 2(b'), the reaction time plays an important role in the formation of CP-AgNPs but has less influence on the CP-AuNPs during the survey period due to the superiority in reducing the ability of $\mathrm{Au}^{3+}\left(E_{A u^{3+} / A u}^{o}=+1.5 \mathrm{~V}\right)$ as compared to $\mathrm{Ag}^{+}$ions $\left(E_{\mathrm{Ag}^{+} / \mathrm{Ag}}^{o}=+0.799 \mathrm{~V}\right)$ [33]. For CPAuNPs, in the first stage $(0-45 \mathrm{~min})$, the longer the reaction time, the higher the maximum UV-Vis absorption was observed. In the case of reaction time longer than $45 \mathrm{~min}$, the decrease in UV-Vis absorbance and the slight shift of maximum wavelength toward larger values indicated the formation of larger size CP-AuNPs. Therefore, $45 \mathrm{~min}$ was chosen as the optimum reaction time for the synthesis of $\mathrm{CP}$ AuNPs. For CP-AgNPs, with the reaction time of 40 to $120 \mathrm{~min}$, the maximum UV-Vis absorbance slightly increased. However, it reached stable values after $120 \mathrm{~min}$. Therefore, it can be concluded that the reaction time of $120 \mathrm{~min}$ is the best choice to perform the synthesis of CP-AgNPs.

Finally, the optimum reaction temperature was investigated in the range of $60-100^{\circ} \mathrm{C}$, while the concentration of metal ions and reaction time were kept constant (1.25 mmol/L and $45 \mathrm{~min}$ for CP-AuNPs; $1.5 \mathrm{mmol} / \mathrm{L}$ and 


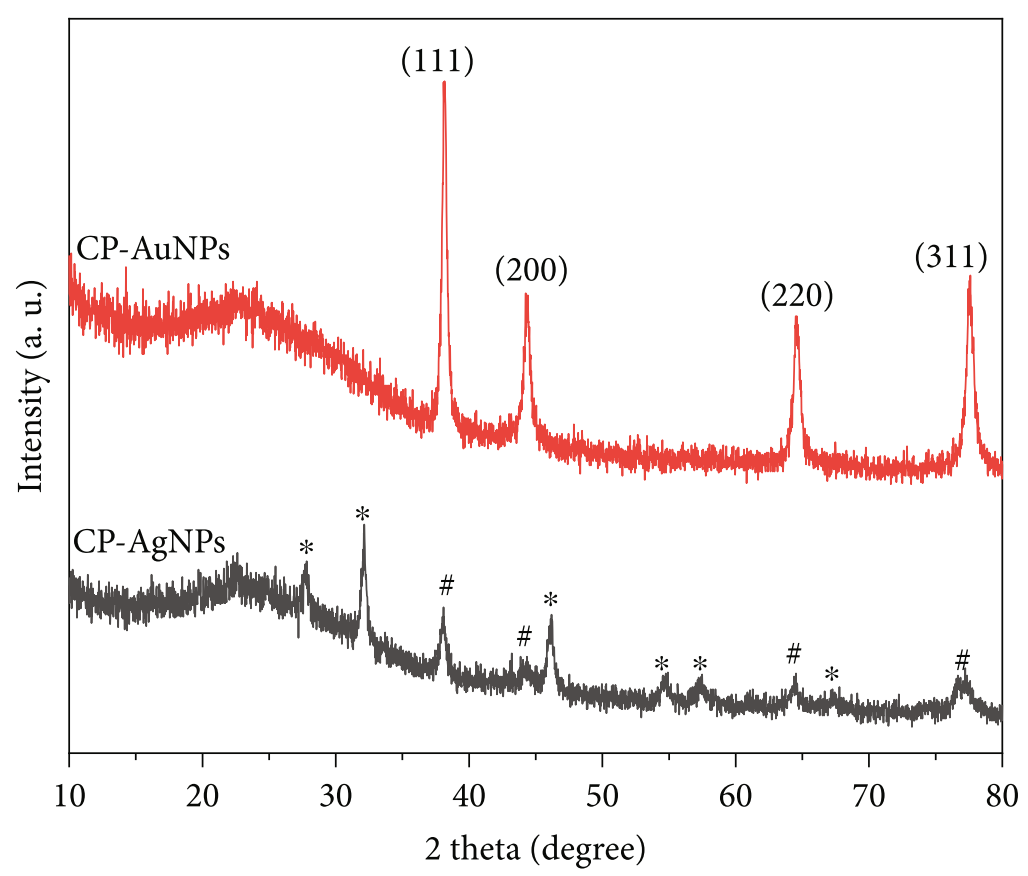

\# AgNPs

* $\mathrm{AgCl}$

(a)

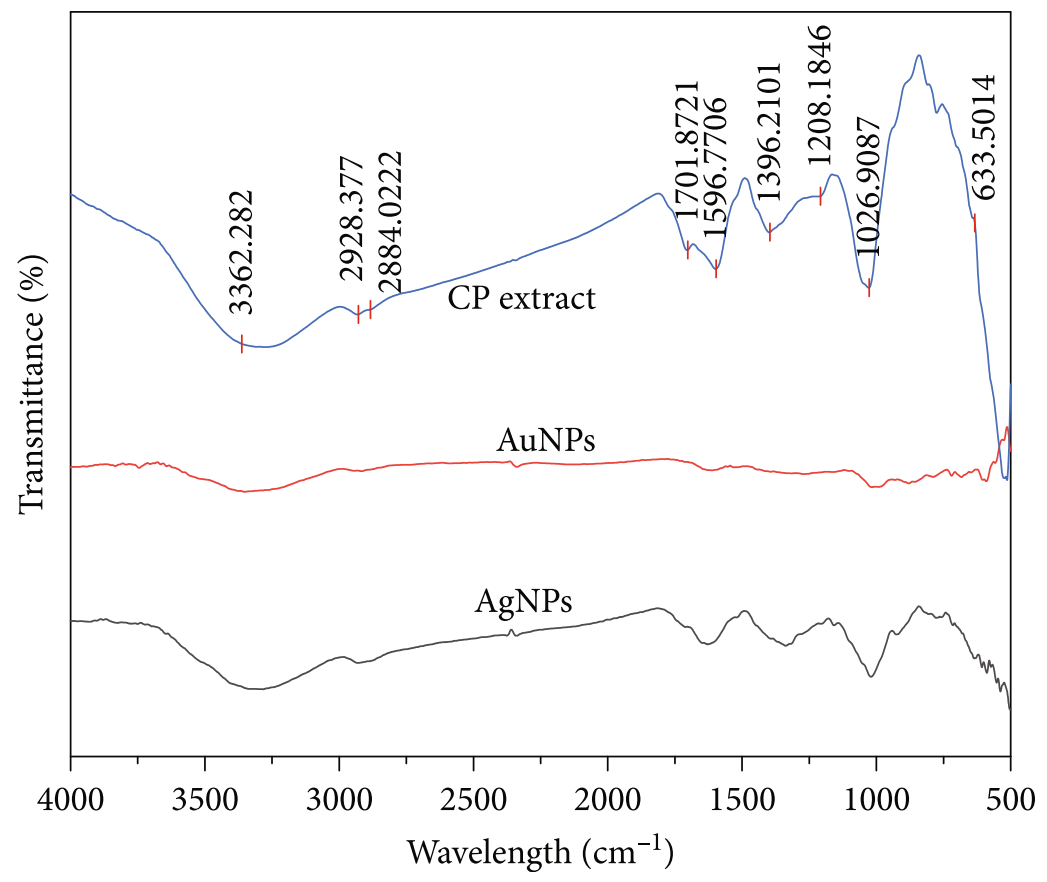

(b)

FIgURE 3: (a) XRD patterns and (b) FTIR spectra of CP-AgNPs and CP-AuNPs.

$120 \mathrm{~min}$ for CP-AgNPs). The obtained results shown in Figures 2(c) and 2(c') indicate that the reaction temperature significantly affected the formation of both CP-AuNPs and $\mathrm{CP}$-AgNPs. The increased temperature in the range of 60 $80^{\circ} \mathrm{C}$ for $\mathrm{Au}^{3+}$ and $\mathrm{Ag}^{+60}-90^{\circ} \mathrm{C}$ provided more energy to the metal ions, leading to its faster conversion into nanoparticles.
At higher temperatures, the ions could move faster, and the number of effective collisions might increase rapidly, resulting in partial coagulation of newly formed nanoparticles with the larger size, causing a decrease in optical density. Therefore, the optimal temperatures of $90^{\circ} \mathrm{C}$ and $80^{\circ} \mathrm{C}$ were chosen for CPAuNPs CP-AgNPs, respectively. 


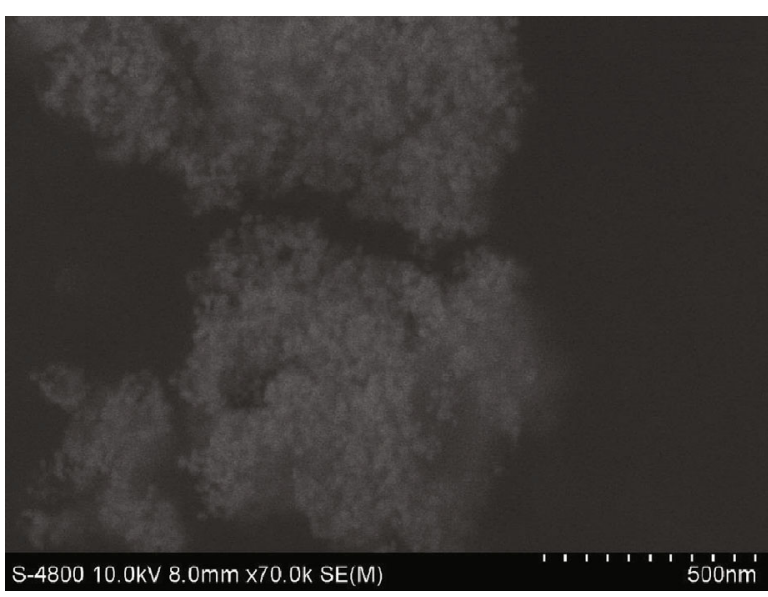

(a)

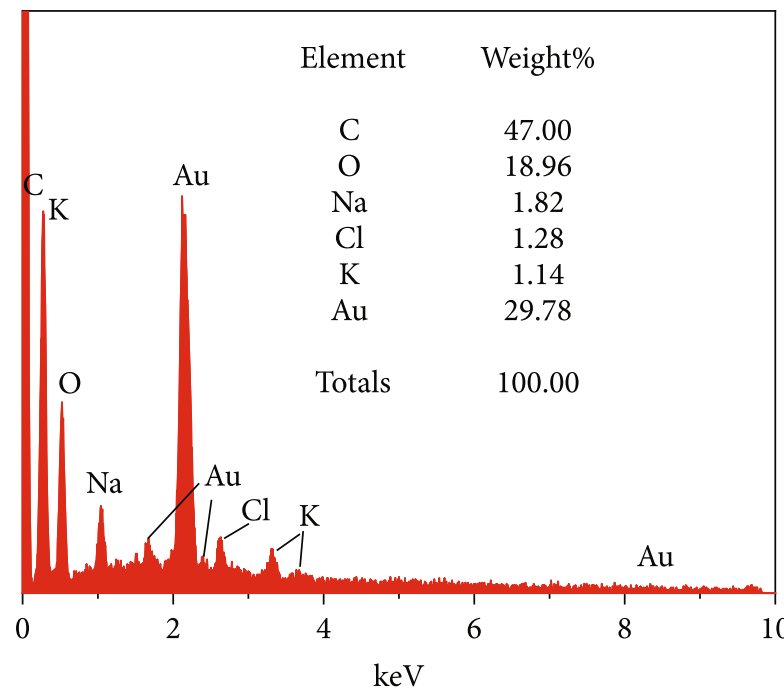

(c)

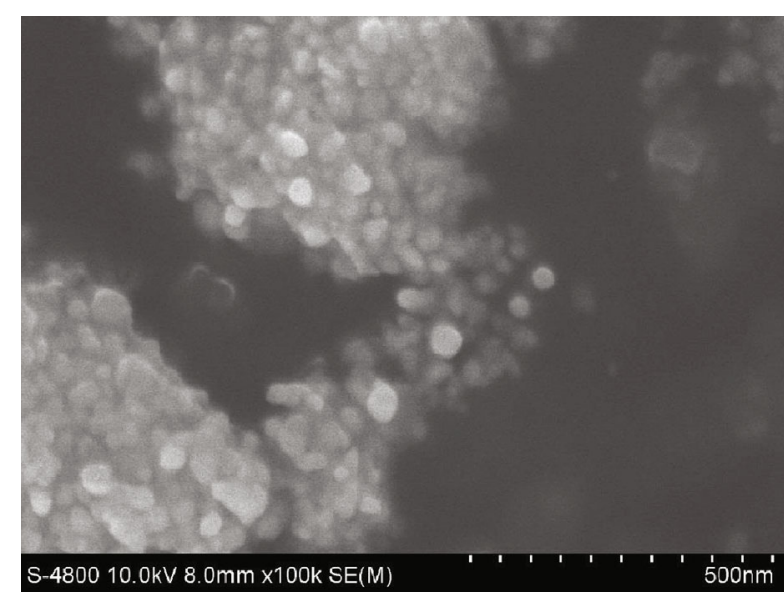

(b)

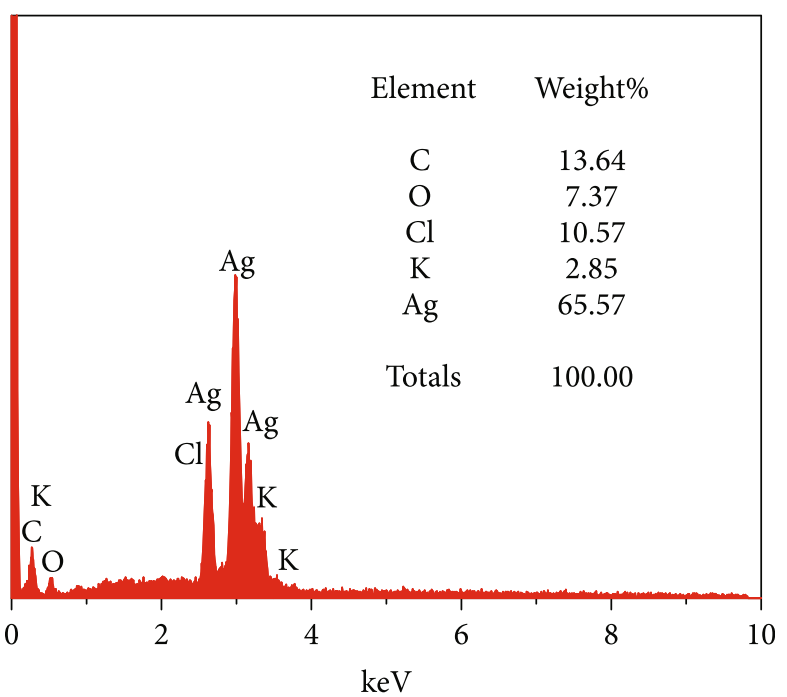

(d)

Figure 4: SEM images (a,b) and EDX spectra (c, d) for CP-AuNPs (a, c) and CP-AgNPs (b, d).

3.2. Characterizations of CP-AgNPs and CP-AuNPs. The features of crystalline structures of CP-AgNPs and CPAuNPs were determined by XRD patterns as presented in Figure 3(a). The XRD pattern of CP-AgNPs shows characteristic peaks at $2 \theta$ angles of $38.12^{\circ}$ (111), $44.27^{\circ}$ (200), $64.42^{\circ}$ (220), and $77.47^{\circ}$ (311) that are typical for the face-centered cubic structure of Ag (ICDD PDF card number 00-0040783) [3] [34]. In addition, the crystalline $\mathrm{AgCl}$ was observed with featured diffraction peaks at $2 \theta$ angle of $27.80^{\circ}, 32.31^{\circ}$, $46.24^{\circ}, 54.80^{\circ}, 57.44^{\circ}$, and $67.30^{\circ}$ due to reaction of $\mathrm{Ag}^{+}$ion with chloride ion presented in CP extract. The presence of $\mathrm{Cl}^{-}$in aqueous plant extract was reported in similar studies [35] [36]. Besides, the detected peaks typical for biosynthesized CP-AuNPs at $38.2^{\circ}$ (111), 44.4 ${ }^{\circ}$ (200), 64.57 $(220)$, and $77.54^{\circ}$ (311) corresponding to the face-centered cubic structure of $\mathrm{Au}$ with the ICDD PDF card number 00-0040784 [35] [36]. In particular, the highest diffraction peaks of CP-AuNPs and CP-AgNPs at $2 \theta$ angle about $38^{\circ}$ indicated that the crystals have a preferred growth direction in Miller indices planes (111). Thus, when determining the full width at half maximum of peaks on (111) plane, the average crystal size of CP-AgNPs and CP-AuNPs can be calculated, according to Debye-Scherrer equation $d=0.9 \lambda / \beta \cos \theta$, where $d$ $(\mathrm{nm})$ is the average crystal size, $\beta$ (radian) is the full width at half maximum, $\lambda(0.1540 \mathrm{~nm})$ is the wavelength of used $\mathrm{CuK} \alpha \mathrm{X}$-ray radiation and " $\theta$ " (degree) is the Bragg diffraction angle. Accordingly, the average crystal size of CPAgNPs and CP-AuNPs is $16 \pm 0.8 \mathrm{~nm}$ and $19.8 \pm 1.2 \mathrm{~nm}$, respectively.

The FTIR spectra of CP-AgNPs, CP-AuNPs, and dried $\mathrm{CP}$ extract as presented in Figure 3(b) show the appearance of major bands at 3362, 2928,1701, 1596, 1396, 1026, and $1208 \mathrm{~cm}^{-1}$. The adsorption peaks of CP-AgNPs and CPAuNPs have a minor difference in position compared to those of dried CP extract due to the presence of metals and the change in chemical functional groups of extract after the reaction. The broad band at $3362 \mathrm{~cm}^{-1}$ is assigned to the $\mathrm{O}-\mathrm{H}$ stretching vibration of phytosteroids, alkaloids, alkyl alcohol glycosides, phenylpropanoid glycosides, polyacetylene glycosides, and polysaccharides presented in the CP-extract 

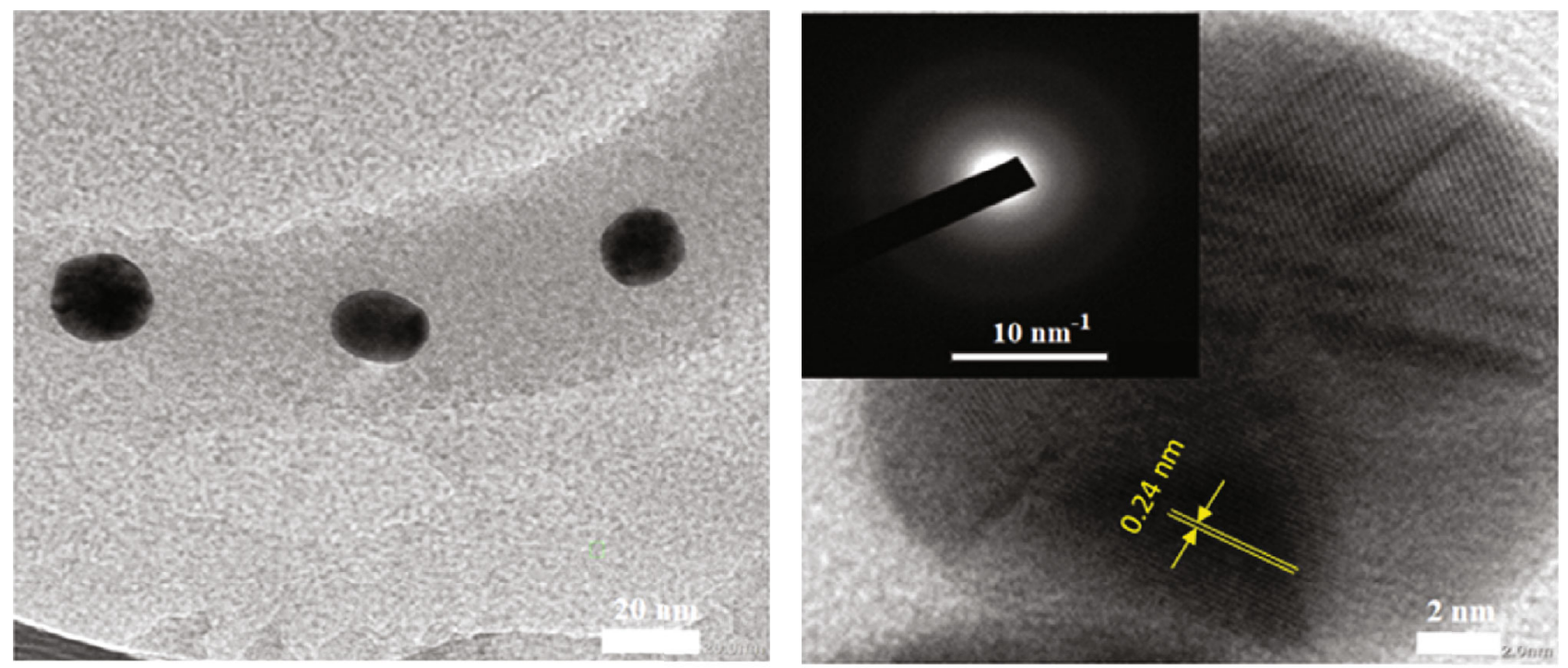

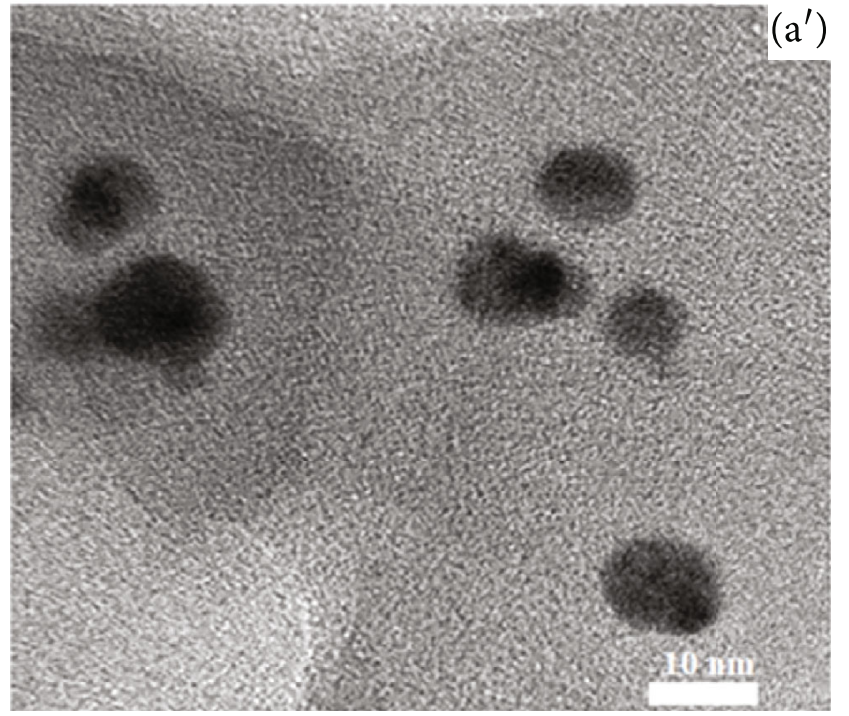

(a)

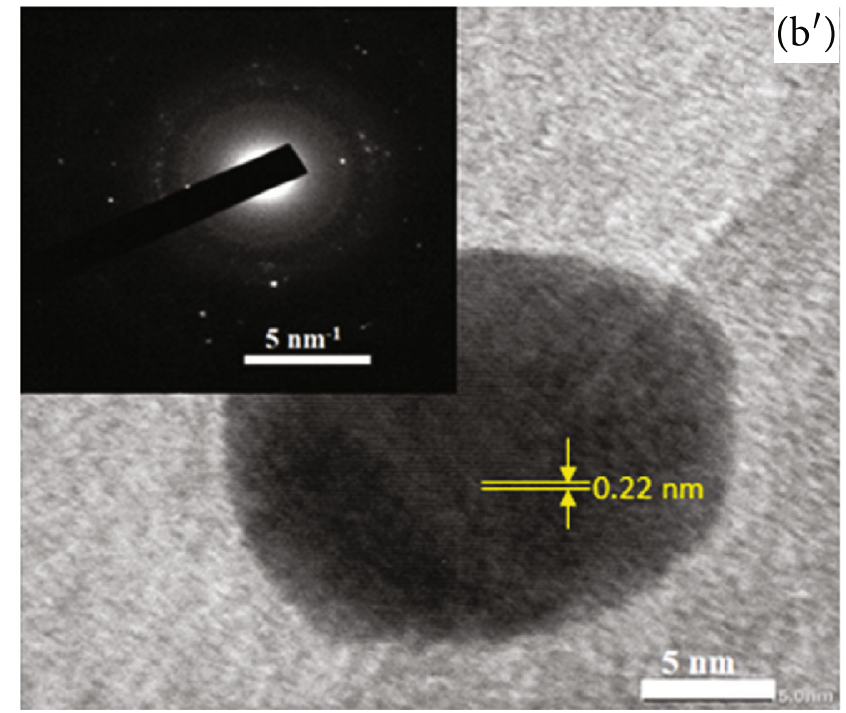

(b)

Figure 5: Continued. 

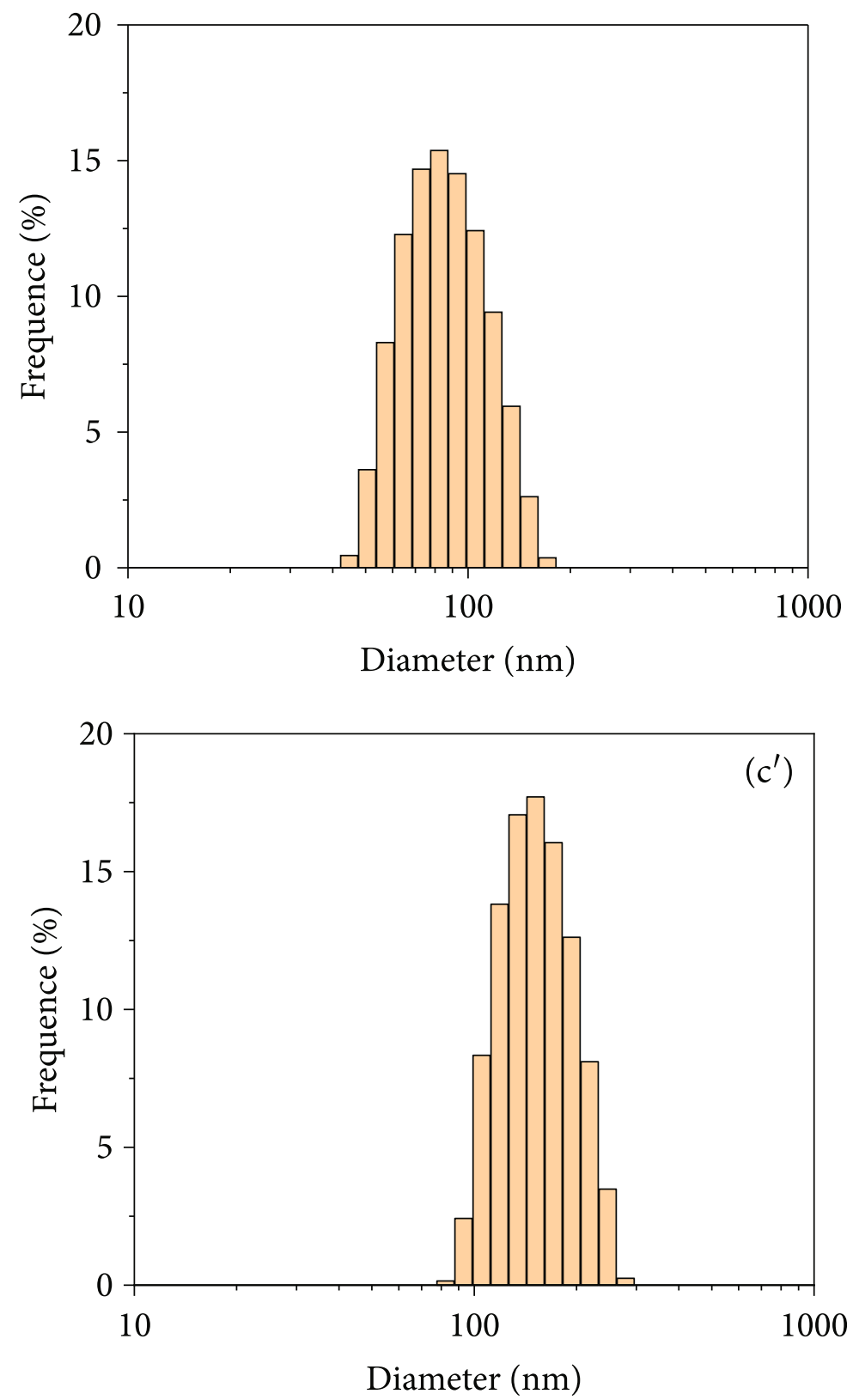

(c)

Figure 5: TEM images ( $a$ and a'), HR-TEM image ( $b$ and b'), SEAD (inset of b and b'), and DLS (c and c') of CP-AuNPs (a, b, and c) and CP$\operatorname{AgNPs}\left(a^{\prime}, b\right.$, and c').

$[37,38]$. Therein, the water-soluble polyol compounds are mainly responsible for the reduction and stabilization of biosynthesized CP-AgNPs and CP-AuNPs [16] [17]. In addition, the absorption bands at 2928, 1396, and $1026 \mathrm{~cm}^{-1}$ characterized for $-\mathrm{CH},-\mathrm{NH}$, and $-\mathrm{CN}$ groups, respectively, were also observed in the FTIR spectra of all samples [39]. The sharp peaks at 1596 and $1701 \mathrm{~cm}^{-1}$ are assigned to $\mathrm{C}=\mathrm{C}$ and $\mathrm{C}=\mathrm{O}$ groups in aromatic compounds [23]. Consequently, the FTIR spectra indicate that the organic constituents of the $\mathrm{CP}$ extract acted as an effective reducing agent and stabilizer for CP-AgNPs and CP-AuNPs nanoparticles.

The surface morphology and element composition of biosynthesized MNPs after undergoing coagulation were expressed by SEM images and EDX analysis, respectively (Figure 4). In this work, SEM microscopy was applied for dried solid CP-AgNPs and CP-AuNPs samples. For this purpose, colloidal stable CP-AgNPs and CP-AuNPs solutions were centrifuged to separate the solids. As presented in SEM images of CP-AuNPs (Figure 4(a)) and CP-AgNPs (Figure 4(b)), both obtained MNPs are spherical in shape and fairly uniform in size. In powdered form, that may be a part of nanoparticles was agglomerated because after the centrifugation at high speed, the organic layer acting as a capping agent could be separated from the metal cores, leading to partial agglomeration. In the EDX spectrum for CPAuNPs (Figure 4(c)), the strong peaks appeared at 1.65, 2.2, 

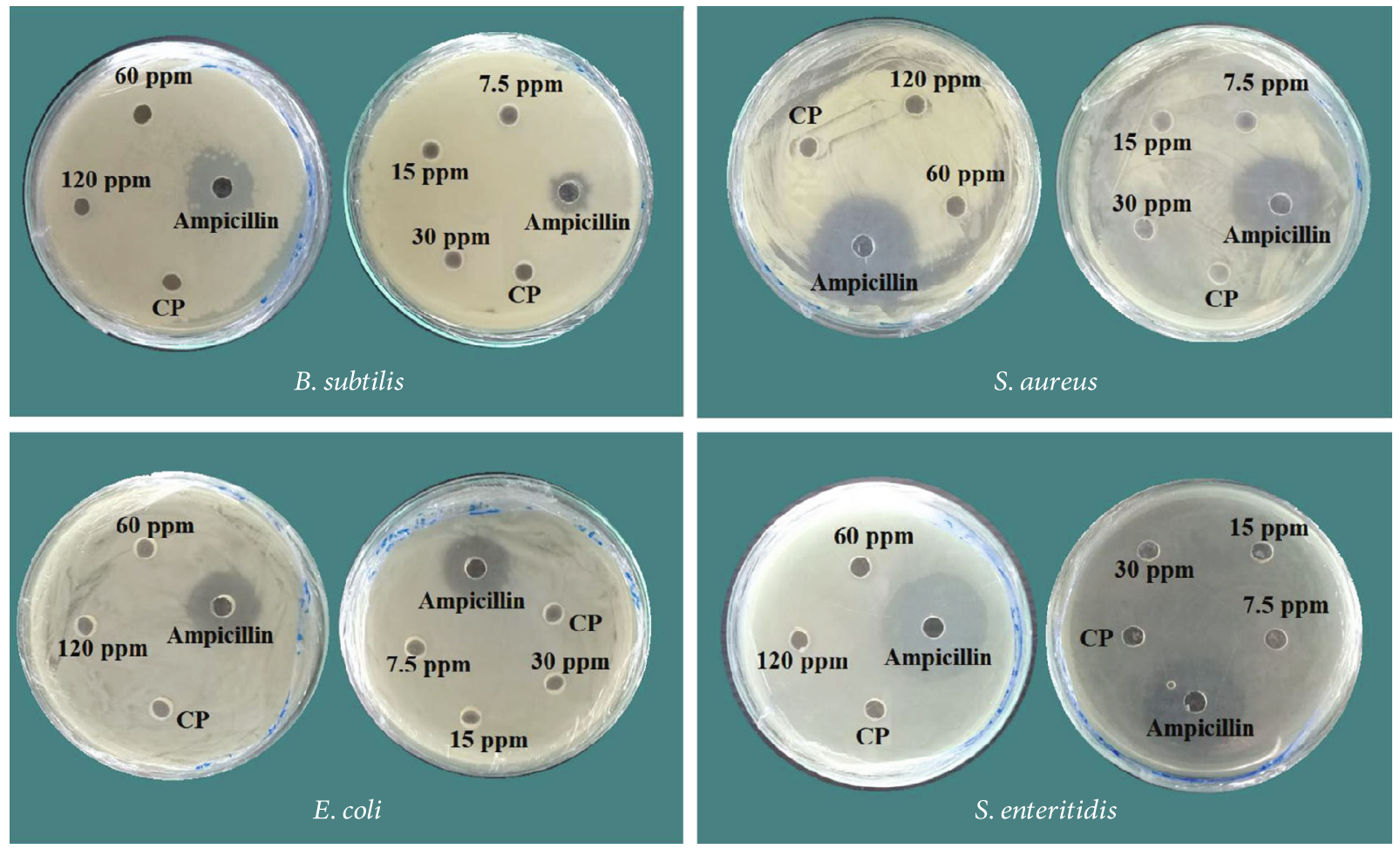

Figure 6: Antibacterial effect of CP-AgNPs at various concentrations.

2.4, 8.5, and $9.75 \mathrm{keV}$ indicated the existence of Au element. In addition, the characteristic signals for elements of $\mathrm{C}$ $(0.4 \mathrm{keV}), \mathrm{O}(0.55 \mathrm{keV})$, and $\mathrm{Cl}(0.2 \mathrm{keV})$ were also observed, confirming the results of previous work about the presence of nutritive constituents in the CP extract [40]. The high content of silver element was certified by characteristic signals at $2.65,2.85$, and $2.95 \mathrm{keV}$ (Figure 4(d)). It should be noted that the average content of gold $(29.78 \mathrm{w} \%)$ is much lower than that of the silver element (65.57 w\%); meanwhile, the average total content of carbon and oxygen in CP-AuNPs $(66 \mathrm{w} \%)$ is superior to that of CP-AgNPs (21.01 w\%). This can be understood because CP-AgNPs contained more capping agents of organic molecules in $\mathrm{CP}$-extract than CP-AuNPs.

The particle size, shape, and distribution of MNPs were evaluated by TEM, SAED, and DLS measurements, and the obtained results are presented in Figure 5. It can be seen from Figures 5(a) and 5(a'), the CP-AgNPs and CP-AuNPs crystals were mostly formed in uniform spheres dispersed well in colloidal solution with the respective average sizes of about $10 \pm 2.5 \mathrm{~nm}$ and $20 \pm 3.2 \mathrm{~nm}$ determined by Debye-Scherrer equation. The crystalline nature of CP-AuNPs and CPAgNPs can be visually observed by HR-TEM and SEAD images (Figures 5(b) and 5(b')). The lattice fringe of CPAuNPs and CP-AgNPs corresponding to the (111) plane had d-spacing of 0.24 and $0.22 \mathrm{~nm}$, respectively. The bright circular rings in SAED images related to (111), (200), (220), and (311) lattice planes also indicated the existence of MNPs in cubic crystal form. Furthermore, the particle size distribution diagrams of CP-AuNPs and CP-AgNPs (Figures 5(c) and $\left.5\left(c^{\prime}\right)\right)$ indicated dynamic diameters of $89 \pm 4.5 \mathrm{~nm}$ and
$112 \pm 5.8 \mathrm{~nm}$, respectively. The difference in particle size between TEM and DLS measurements confirmed that CPAuNPs and CP-AgNPs in colloidal solutions were covered with a thick layer of organic molecules acted as a stabilizing agent. In fact, both CP-AgNPs and CP-AuNPs samples in colloidal form were stable for more than 3 weeks under normal room conditions at $25^{\circ} \mathrm{C}$. The thickness of this organic matter layer covering CP-AgNPs sample is larger than that of CP-AuNPs sample. This is confirmed by the difference in EDX results of total content of carbon and oxygen presented in the two MNPs.

3.3. Antibacterial Assay. Antibacterial activity of both biosynthesized MNPs in the form of colloidal solutions was tested against four bacterial strains: two Gram-positive ( $B$. subtilis and S. aureus) and two Gram-negative (S. Enteritidis and $E$. Coli) with various MNPs concentrations. The antibacterial effects of CP-AuNPs and CP-AgNPs at various concentrations are illustrated in Figures 6 and 7, respectively. It has been found that CP-AuNPs did not exhibit bioactivity against any bacterial strain even at the highest concentration $(120 \mathrm{ppm})$, while the colloidal sample of CP-AgNPs possessed a good antibacterial activity against three tested bacterial strains. The observed nonantibacterial activity of $\mathrm{CP}$ AuNPs might be due to its minimum concentration required for antibacterial performance is still higher than the optimum. In addition, the surface area, size, and shape of MNPs can also affect bacterial inhibition [22, 41, 42]. For CPAgNPs, a high antibacterial activity against three bacteria strains including B. subtilis, S. aureus, and E. coli was observed; however, it did not inhibit $S$. enteritidis at tested 

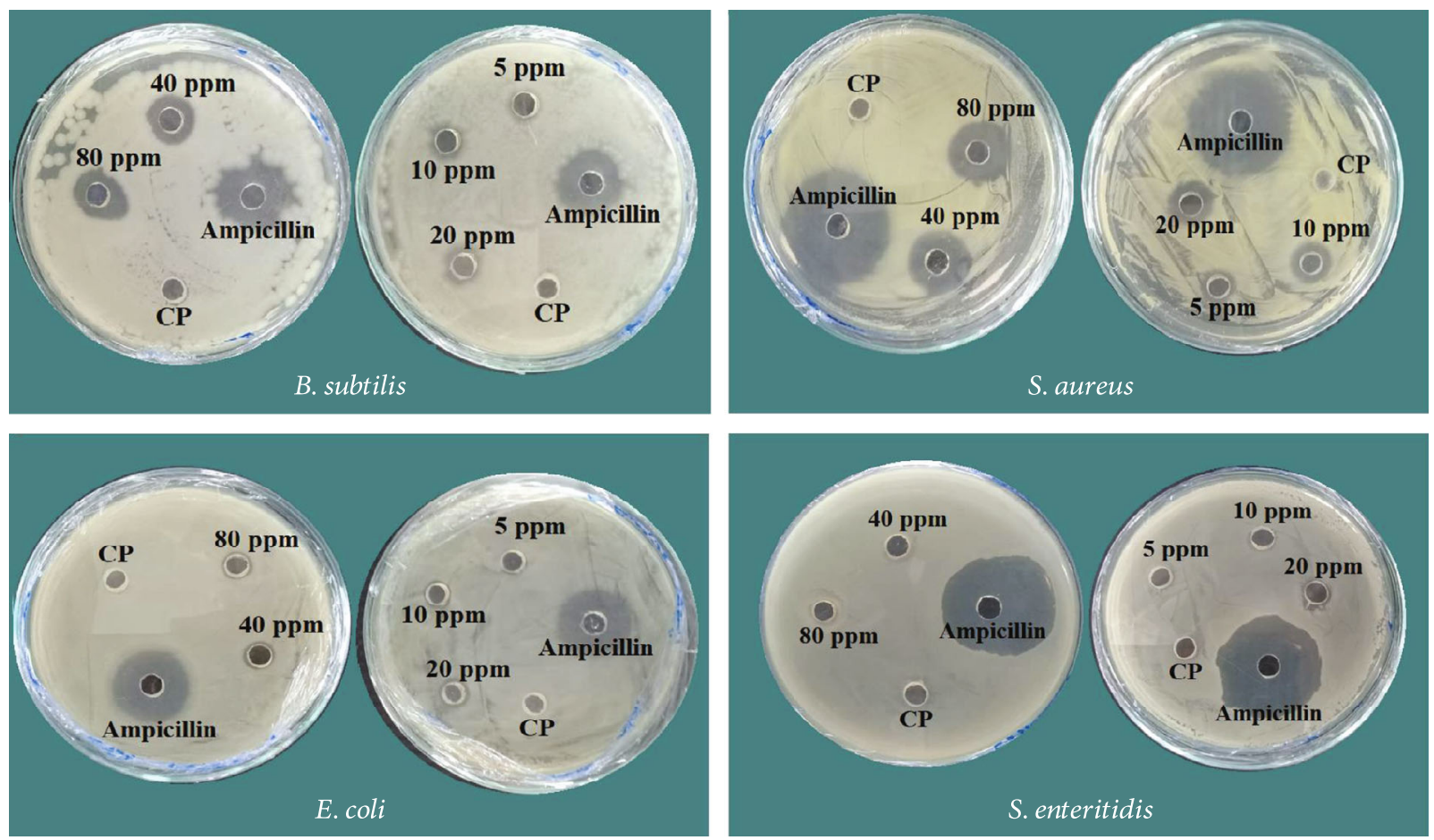

Figure 7: Antibacterial effect of CP-AgNPs at various concentrations.

TABLE 1: Comparative antibacterial activity of AgNPs.

\begin{tabular}{|c|c|c|c|c|c|}
\hline Bacterial strains & Plant part & Size $(\mathrm{nm})$ & Concentration of AgNPs (ppm) & Zone of inhibition $(\mathrm{mm})$ & References \\
\hline \multirow{7}{*}{ S. aureus } & Capparis spinosa L. leaf & $5-30$ & 100 & 14.1 & {$[43]$} \\
\hline & Annona squamosa & $7-8$ & 25 & 19.2 & [3] \\
\hline & Aspergillus fumigatus & 94 & 7 & 27.0 & {$[44]$} \\
\hline & Parkia speciosa & 35 & 100 & 10.0 & {$[45]$} \\
\hline & Corn-cob & 11 & 8 & 15.0 & {$[30]$} \\
\hline & Albizia procera & 6.18 & 100 & 18.5 & {$[22]$} \\
\hline & Codonopsis pilosula & 10 & 80 & $17.0 \pm 1.2$ & This work \\
\hline \multirow{5}{*}{ B. cereus } & Capparis spinosa L. leaf & $5-30$ & 100 & 13.1 & {$[43]$} \\
\hline & Annona squamosa & $7-8$ & 25 & 17.8 & [3] \\
\hline & Parkia speciosa & 35 & 100 & 5.0 & [45] \\
\hline & Corn-cob & 11 & 8 & 16.0 & {$[30]$} \\
\hline & Codonopsis pilosula & 10 & 80 & $12.0 \pm 0.85$ & This work \\
\hline \multirow{7}{*}{ E. coli } & Aspergillus fumigatus & 94 & 7 & 25.0 & {$[44]$} \\
\hline & Capparis spinosa $L$. leaf & $5-30$ & 100 & 16.0 & {$[43]$} \\
\hline & Annona squamosa & $7-8$ & 25 & 12.0 & [3] \\
\hline & Parkia speciosa & 35 & 100 & 9.0 & {$[3]$} \\
\hline & Albizia procera & 6.18 & 100 & 13.5 & {$[22]$} \\
\hline & Holoptelea integrifolia & $32-38$ & 400 & 10.0 & [41] \\
\hline & Codonopsis pilosula & 10 & 80 & $7.0 \pm 0.42$ & This work \\
\hline \multirow{4}{*}{ S. enteritidis } & Capparis spinosa L. leaf & $5-30$ & 100 & 15.1 & {$[43]$} \\
\hline & Corn-cob & 11 & 8 & 11.0 & {$[30]$} \\
\hline & Holoptelea integrifolia & $32-38$ & 400 & 13.0 & [41] \\
\hline & Codonopsis pilosula & 10 & 80 & 0.0 & This work \\
\hline
\end{tabular}




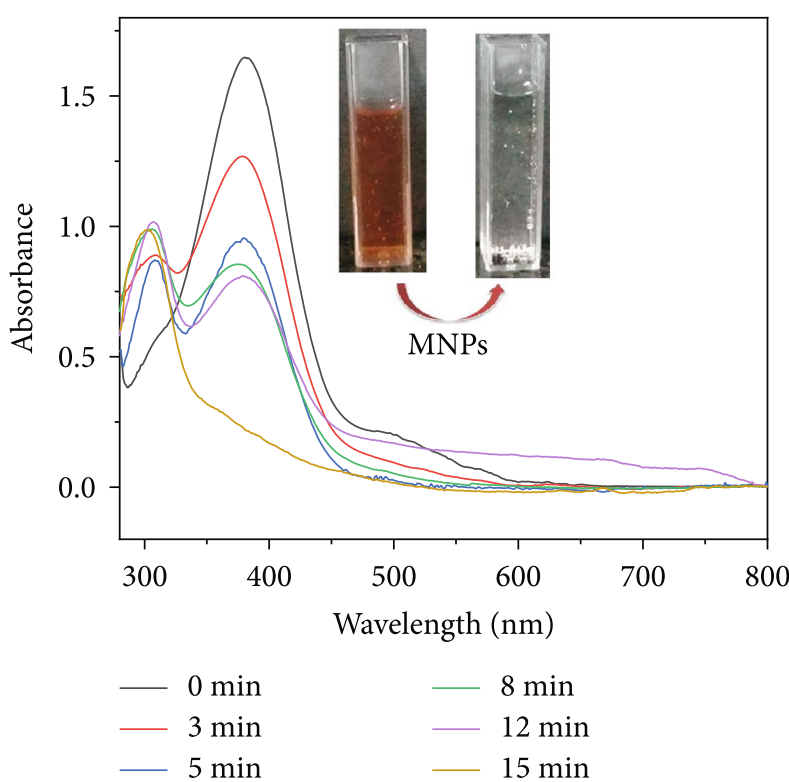

(a)

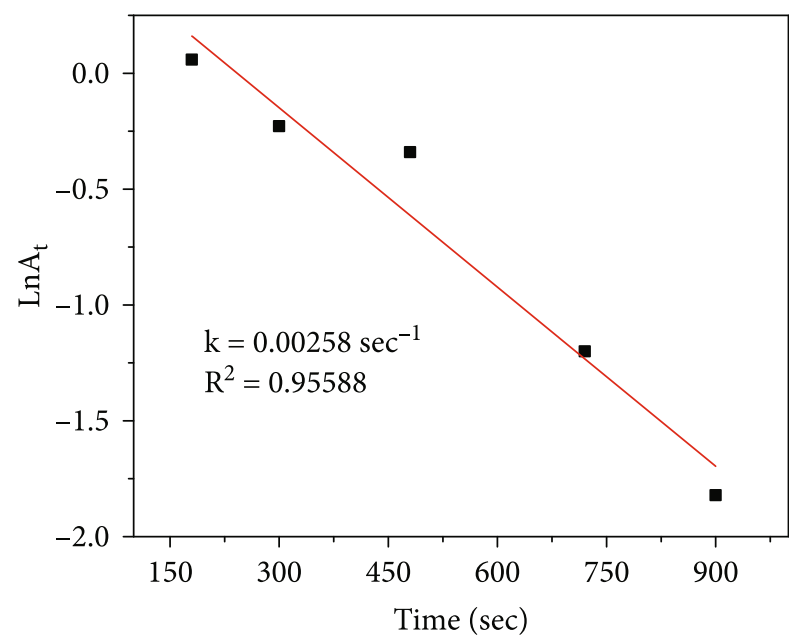

(c)

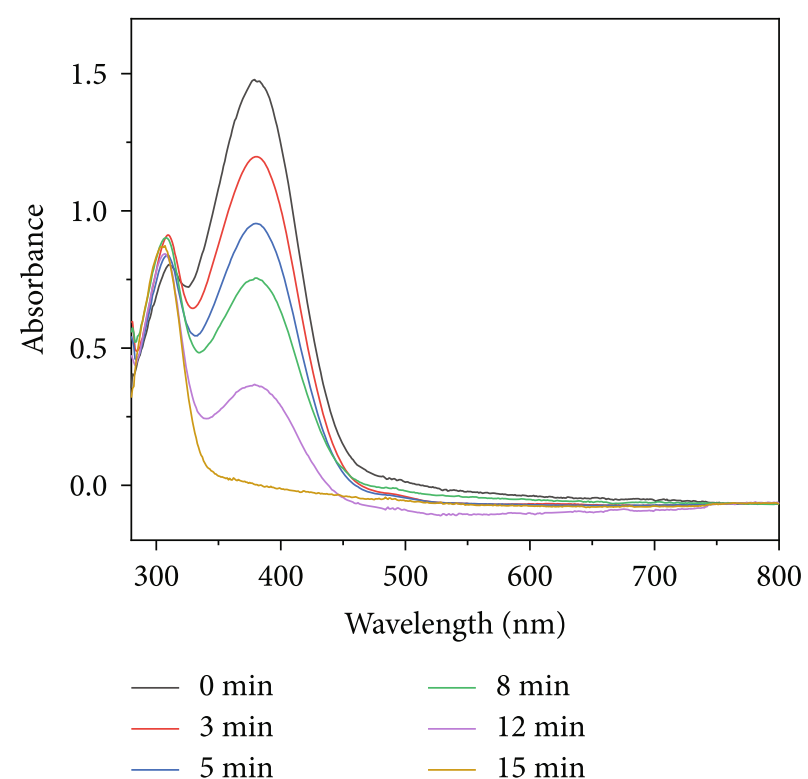

(b)

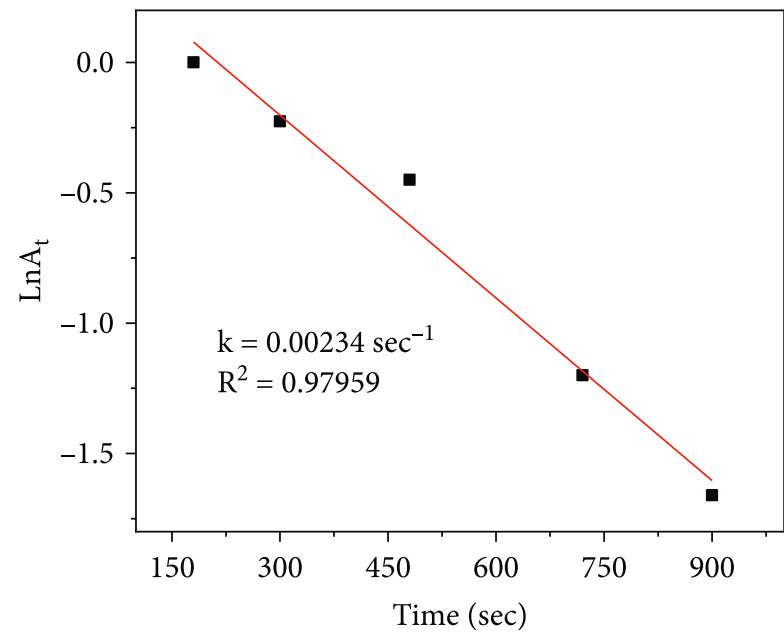

(d)

FIgURE 8: UV-Vis spectra $(a, b)$ and first-order kinetics (c, d) for degradation of 1,4-DNB by $\mathrm{NaBH}_{4}$ in the presence of CP-AuNPs (a, c) and CP-AgNPs (b, d).

concentrations. Moreover, the antibacterial activity increased with an increase in the concentration of the biosynthesized CP-AgNPs. The comparison of antibacterial activity for the CP-AgNPs with those reported in previous works are listed in Table 1. It is evident that the antibacterial activity of CPAgNPs depends not only on AgNPs size but also strongly on the stabilizing agents.

3.4. Catalytic Performance for Reduction of Nitrophenols. Resistant substituted phenols, especially nitrophenols, are widely used in chemical industries for many applications. However, they can cause a serious threat to the aquatic animals even at low concentrations due to high toxicity and difficulty in degradation [46]. In this work, the catalytic performance of CP-AgNPs and CP-AuNPs was evaluated by degradation of 2 -NP, $3-\mathrm{NP}, 4-\mathrm{NP}$, and 1,4-DNB using
$\mathrm{NaBH}_{4}$ as reductant. It is well known that the reduction of those organic substances by $\mathrm{NaBH}_{4}$ without a catalyst is a thermodynamically favorable reaction but kinetically unfavorable due to the kinetic barrier between the $\mathrm{BH}_{4}{ }^{-}$and nitrophenolate ions [14]. This barrier can be quickly overcome by using AgNPs and AuNPs via an electron transfer mechanism [28]. The results for the reduction of 1,4-DNB, 2-NP, 3-NP, and $4-\mathrm{NP}$ by $\mathrm{NaBH}_{4}$ in the presence of the biosynthesized CP-AgNPs and CP-AuNPs are shown in Figures 8-11, respectively.

3.4.1. Catalytic Activity of CP-AgNPs and CP-AuNPs for Reduction of 1,4-DNB. After adding $\mathrm{NaBH}_{4}$ to the yellowish 1,4-DNB solution, the color of the solution turns into dark red, and the maximum absorbance peak at $380 \mathrm{~nm}$ appeared regardless of that the decomposition reaction has not started 


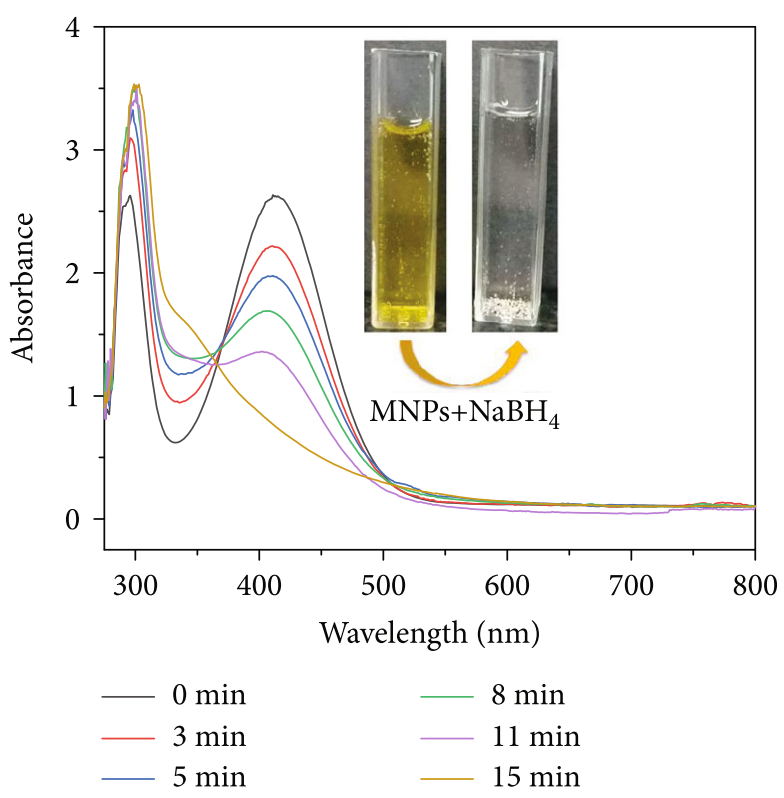

(a)

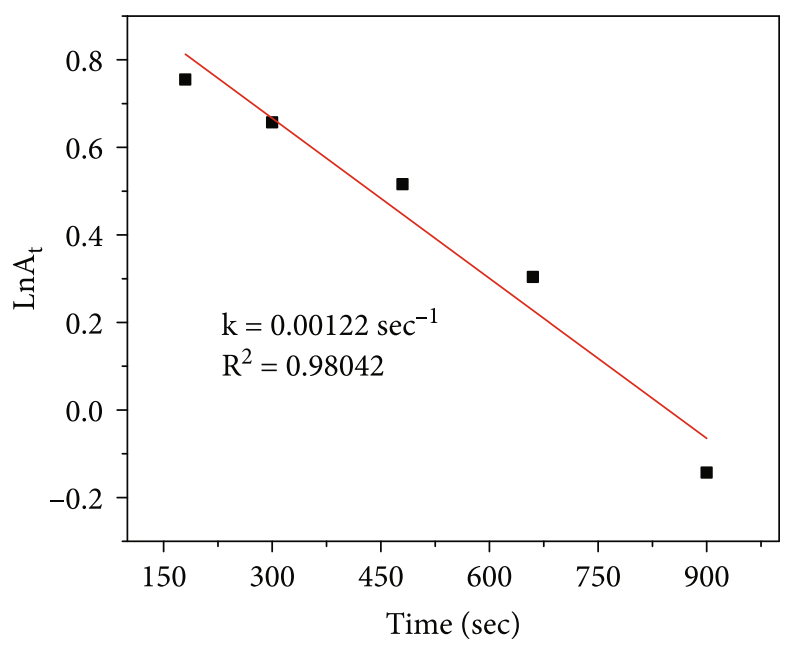

(c)
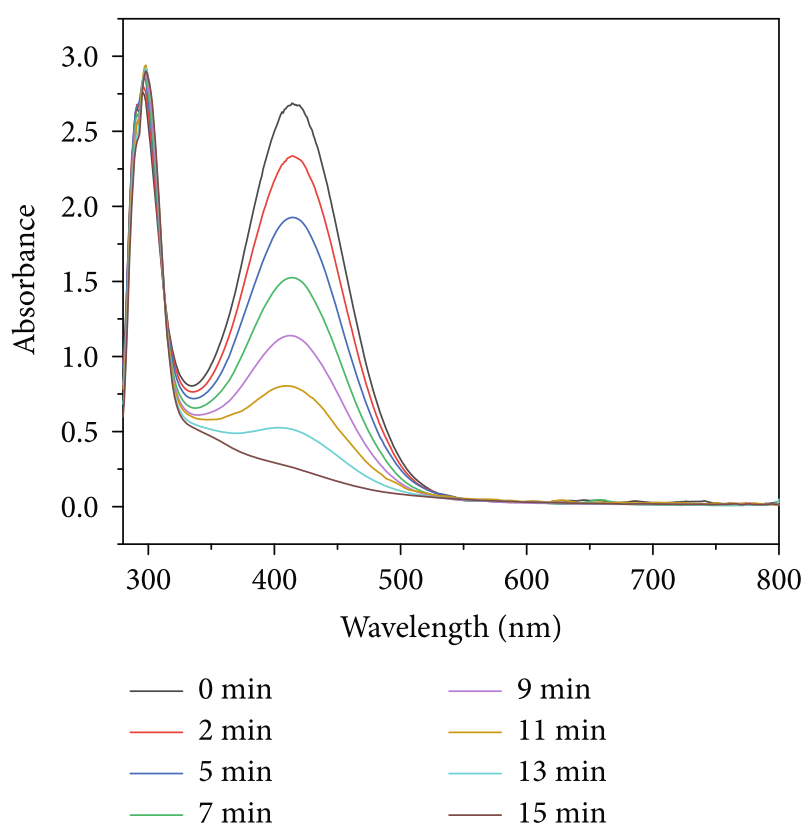

(b)

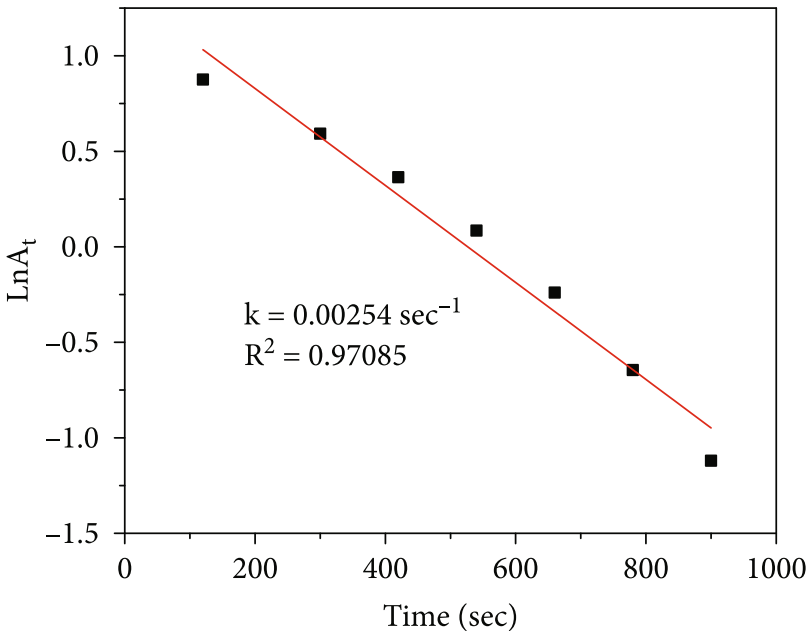

(d)

Figure 9: UV-Vis spectra $(a, b)$ and first-order kinetics $(c, d)$ for degradation of 2-NP by $\mathrm{NaBH}_{4}$ in the presence of CP-AuNPs $(\mathrm{a}, \mathrm{c})$ and $\mathrm{CP}$ $\operatorname{AgNPs}(b, d)$.

yet. As soon as CP-AgNPs and CP-AuNPs were added, the color of the solution gradually disappears. Figure 8 shows the UV-Vis spectra and first-order kinetics for the degradation of $1,4-\mathrm{DNB}$ by $\mathrm{NaBH}_{4}$ in the presence of CP-AuNPs and CP-AgNPs. A gradual decrease in UV-Vis maximum absorbance at the wavelength of $380 \mathrm{~nm}$ and a simultaneous increase in peak at $300 \mathrm{~nm}$ demonstrated the occurrence of 1,4-DNB decomposition process with the formation of 1,4-diaminobenzene. The results indicated that the 1,4-diaminobenzene decomposition in the presence of CP-AgNPs and CP-AuNPs was completed within 15 minutes as evidenced by near-zero absorbance at $380 \mathrm{~nm}$ (Figures 8(a) and 8(b)). The linear relationship can be observed from the equation $\ln (A t)$ over the reaction time (Figures 8(b) and $8(\mathrm{~d})$ ), wherein the first-order reaction rate constants $k$ were determined as $(2.58 \pm 0.15) \times 10-3$ $\mathrm{sec}-1$ for CP-AuNPs and $(2.34 \pm 0.18) \times 10-3 \mathrm{sec}-1$ for CP-AgNPs.

3.4.2. Catalytic Activity of CP-AgNPs and CP-AuNPs for Reduction of 2-NP. Quite similarly as above, the color of 2-NP solution was changed from light to dark yellow after the addition of $\mathrm{NaBH}_{4}$ due to the formation of 2nitrophenolate ions in a slightly alkaline environment without reaction. UV-Vis spectroscopy (Figures 9(a) and 9(b)) shows a gradual decrease in absorbance at $410 \mathrm{~nm}$ and a simultaneous increase in a new peak at $290 \mathrm{~nm}$, suggesting that 2-NP was reduced to 2-aminophenol. The reduction reaction was also completed within $15 \mathrm{~min}$ with the reaction rate constants $k=(2.54 \pm 0.13) \times 10-3 \mathrm{sec}-1$ for 


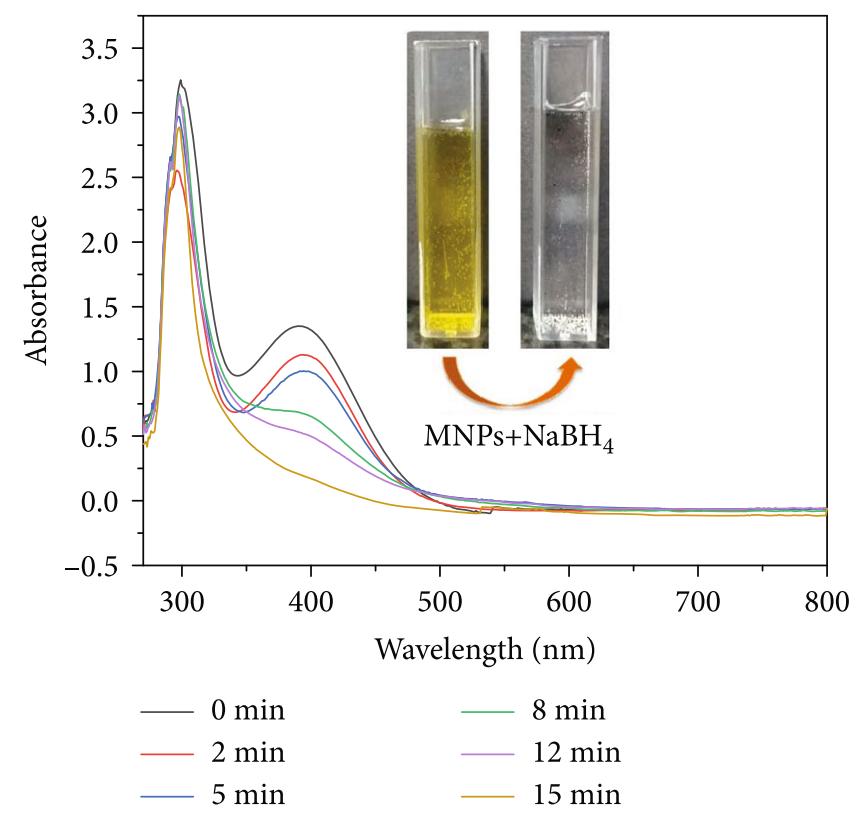

(a)

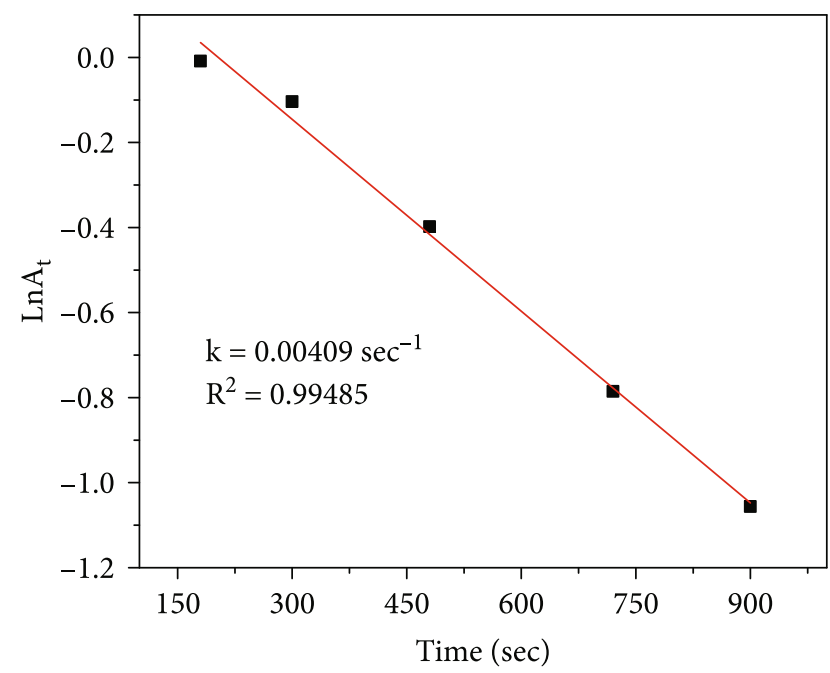

(c)

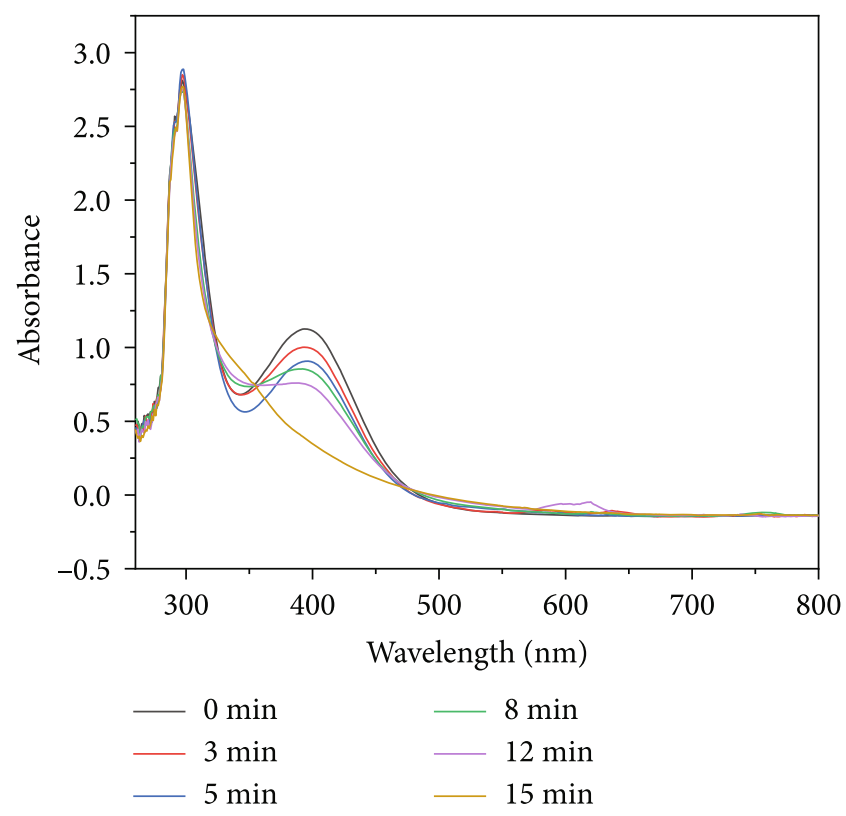

(b)

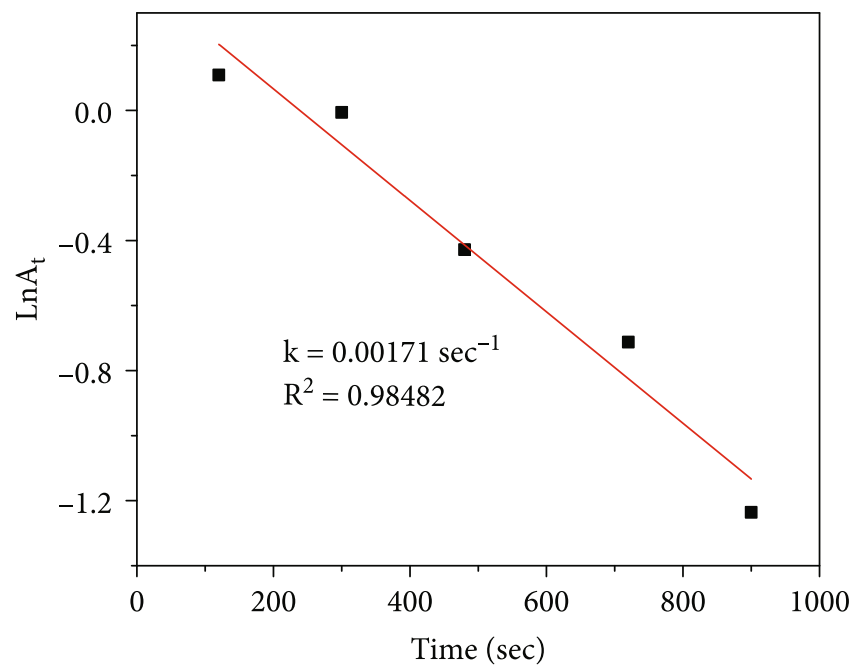

(d)

Figure 10: UV-Vis spectra (a, b) and first order kinetics (c, d) of 3-NP by $\mathrm{NaBH}_{4}$ in the presence of CP-AuNPs (a, c) and CP-AgNPs (b, d).

CP-AuNPs and $k=(1.22 \pm 0.24) \times 10-3 \mathrm{sec}-1$ for $\mathrm{CP}-$ AgNPs (Figures 9(c) and 9(d)).

3.4.3. Catalytic Activity of CP-AgNPs and CP-AuNPs for Reduction of 3-NP. For 3-NP, the color of the solution turned from pale yellow to yellow by the addition of $\mathrm{NaBH}_{4}$ and simultaneously disappeared in the presence of CP-AgNPs and CP-AuNPs after $13 \mathrm{~min}$. UV-Vis spectroscopy shows changes in UV-Vis maximum absorbance during the reaction (Figures 10(a) and 10(c)), wherein a gradual decrease in absorbance at $390 \mathrm{~nm}$ and a simultaneous increase in a new peak at $300 \mathrm{~nm}$ suggests that the decomposition of 3NP occurred to form 3-aminophenol with the first-order reaction rate constants $k=(1.71 \pm 0.075) \times 10-3 \mathrm{sec}-1$ for CP-AuNPs and $k=(4.09 \pm 0.16) \times 10-3 \mathrm{sec}-1$ for CPAgNPs (Figures 10(b) and 10(d)).
3.4.4. Catalytic Activity of $C P-A g N P s$ and $C P-A u N P s$ for Reduction of 4-NP. For the reduction of $4-\mathrm{NP}$ by $\mathrm{NaBH}_{4}$ using MNPs as a catalyst, UV-Vis spectroscopy showed a decrease in absorbance at $400 \mathrm{~nm}$ characterized for the dark yellow 4-nitrophenolate solution and the simultaneous increase in the peak at $300 \mathrm{~nm}$ related to transparent 4aminophenol (Figures 11(a) and 11(b)). It has been found that the 4-NP reduction in the presence CP-AuNPs and $\mathrm{CP}$-AgNPs completed within 14 minutes with reaction rate constant values of $(3.84 \pm 0.32) \times 10-3 \mathrm{sec}-1$ and $(2.88 \pm$ $0.34) \times 10-3 \mathrm{sec}-1$, respectively (Figures $11(\mathrm{c})$ and $11(\mathrm{~d})$ ). Thus, the catalytic ability of CP-AuNPs showed the best performance for the reduction of 4-NP, almost double that of 3-NP. Meanwhile, CP-AgNPs exhibited the best catalytic activity with $3-\mathrm{NP}$ by 3.35 times greater than that of 2-NP. The CP-AuNPs revealed better catalytic performance than 


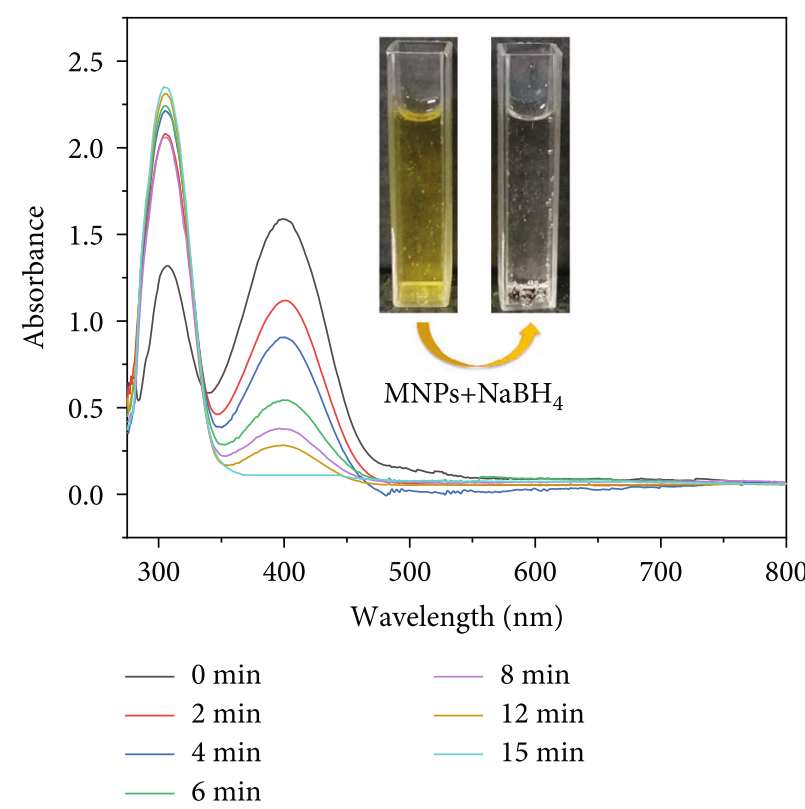

(a)

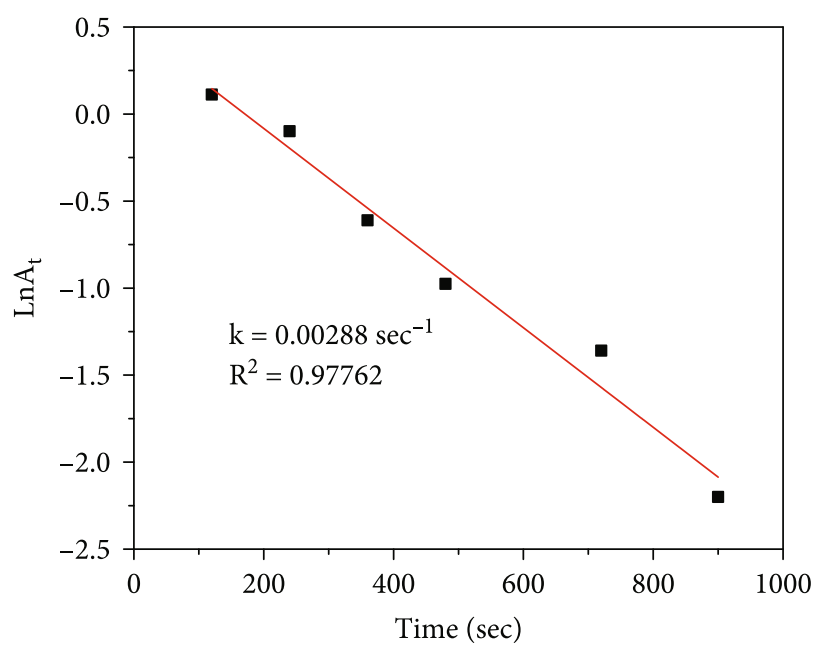

(c)

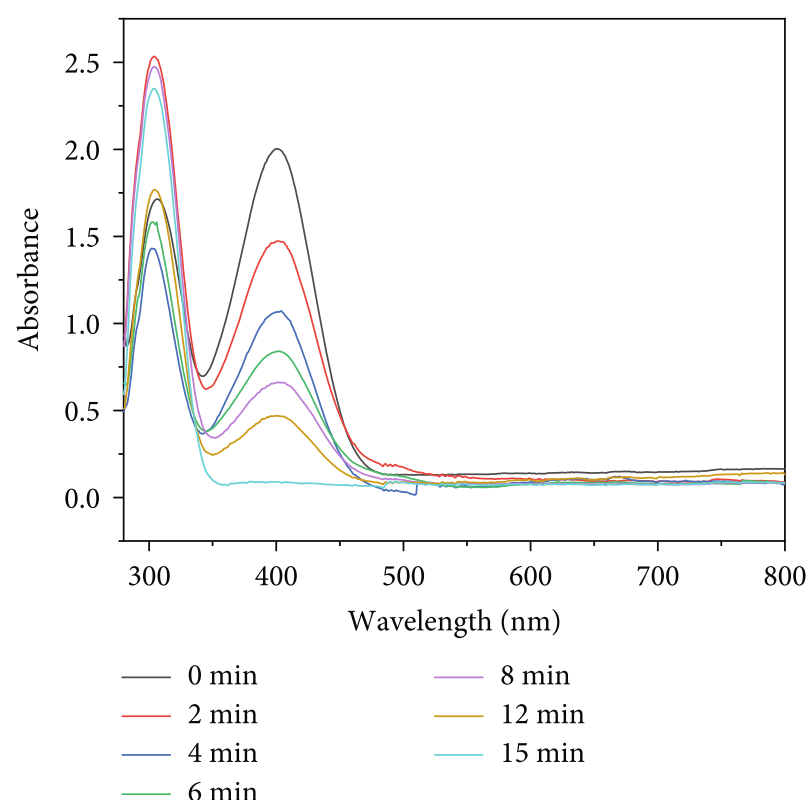

(b)

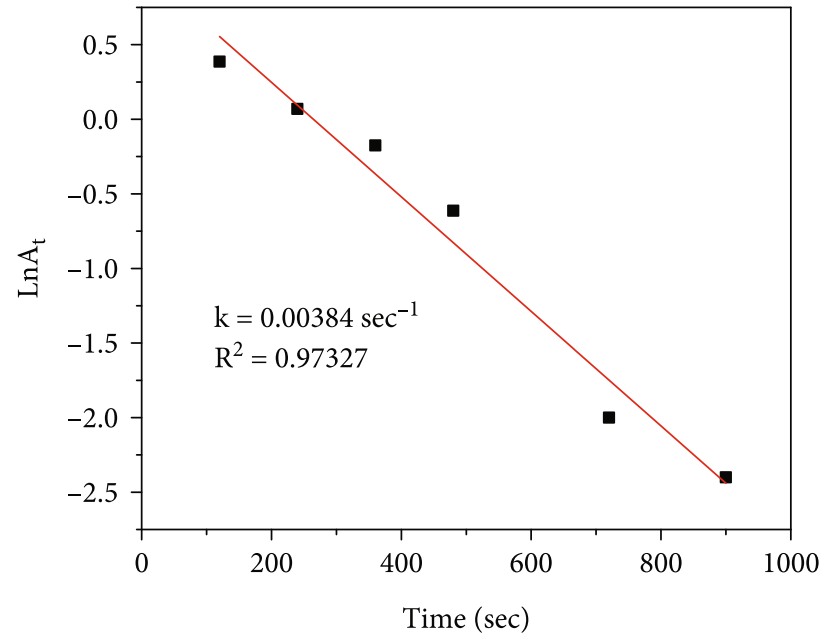

(d)

Figure 11: UV-Vis spectra $(a, b)$ and first-order kinetics (c, d) of 4-NP by $\mathrm{NaBH}_{4}$ in the presence of CP-AuNPs (a, c) and CP-AgNPs (b, d).

CP-AgNPs for all nitrophenols, while the reduction time was only slightly different. The CP-AuNPs and CP-AgNPs biosynthesized by the extract of CP also demonstrated a good catalyst performance in comparison with those of AuNPs and AgNPs prepared by the extract from different plants (Table 2).

3.4.5. The Reusability of MNPs. The reusability of catalysts based on MNPs is especially necessary for practical applications by means of confirming their stability for long-term use and reducing the cost. In this work, the recyclable performance was tested for four reaction recycles toward the reduction of 4-NP as representative for nitrophenols.

After the initial use, the MNPs were recovered by centrifugation, washed carefully with ethanol, and applied for reuse according to the mentioned above procedure. In the first reuse for both CP-AuNPs and CP-AgNPs, the UV-Vis absorbance peak at $400 \mathrm{~nm}$ corresponded to yellow 4-NP disappeared in about 20 minutes and a peak at $300 \mathrm{~nm}$ increased over time, indicating the formation of colorless 4 -aminophenol. For the subsequent reuses, the same results were also observed. However, the reduction of 4-NP lasted longer, about 30 and $35 \mathrm{~min}$, respectively. The recycling process confirmed a good recyclability of biosynthesized MNPs in the reduction of 4NP after 4 successive recycles with the yield greater than 96\% for CP-AuNPs and 95\% for CP-AuNPs (Figure 12).

\section{Conclusions}

In this study, the aqueous extract from Codonopsis pilosula roots was successfully used as both reducing and stabilizing agents for the synthesis of AgNPs and AuNPs. The obtained biosynthesized MNPs were formed in a spherical 
TABLE 2: Comparative catalytic performance of biosynthesized MNPs for reduction of polyphenols by $\mathrm{NaBH}_{4}$.

\begin{tabular}{|c|c|c|c|c|c|}
\hline Pollutants & MNPs & Plant part & Average size $(\mathrm{nm})$ & $k\left(\sec ^{-1}\right)$ & References \\
\hline \multirow{2}{*}{ 1,4-DNB } & AuNPs & \multirow{2}{*}{ Codonopsis pilosula root } & 20 & $(2.58 \pm 0.15) \times 10^{-3}$ & \multirow{2}{*}{ This work } \\
\hline & AgNPs & & 10 & $(2.34 \pm 0.18) \times 10^{-3}$ & \\
\hline \multirow{5}{*}{ 2-NP } & AuNPs & Seaweed Lobophora variegata & $2-12$ & $1.21 \times 10^{-3}$ & {$[27]$} \\
\hline & AuNPs & \multirow{2}{*}{ Corn-cob } & 35 & $3.00 \times 10^{-3}$ & \multirow{2}{*}[30]{} \\
\hline & AgNPs & & 11 & $2.10 \times 10^{-3}$ & \\
\hline & AuNPs & \multirow{2}{*}{ Codonopsis pilosula root } & 20 & $(1.22 \pm 0.24) \times 10^{-3}$ & \multirow{2}{*}{ This work } \\
\hline & AgNPs & & 10 & $(2.54 \pm 0.13) \times 10^{-3}$ & \\
\hline \multirow{5}{*}{$3-\mathrm{NP}$} & AuNPs & Seaweed Lobophora variegata & $2-12$ & $4.50 \times 10^{-3}$ & {$[37]$} \\
\hline & AuNPs & \multirow{2}{*}{ Corn-cob } & 35 & $8.00 \times 10^{-3}$ & \multirow{2}{*}[30]{} \\
\hline & AgNPs & & 11 & $2.80 \times 10^{-3}$ & \\
\hline & AuNPs & \multirow{2}{*}{ Codonopsis pilosula root } & 20 & $(4.09 \pm 0.16) \times 10^{-3}$ & \multirow{2}{*}{ This work } \\
\hline & AgNPs & & 10 & $(1.71 \pm 0.075) \times 10^{-3}$ & \\
\hline \multirow{11}{*}{$4-\mathrm{NP}$} & AuNPs & Coffea arabica seed & $16-22$ & $5.22 \times 10^{-3}$ & {$[1]$} \\
\hline & AuNPs & \multirow{2}{*}{ Burdock root } & 24.7 & $6.87 \times 10^{-3}$ & \multirow{2}{*}[29]{} \\
\hline & AgNPs & & 21.3 & $6.77 \times 10^{-3}$ & \\
\hline & AuNPs & \multirow{2}{*}{ L. indica leaf } & 14.5 & $1.30 \times 10^{-3}$ & \multirow{2}{*}[35]{} \\
\hline & AgNPs & & 13.5 & $2.10 \times 10^{-3}$ & \\
\hline & AuNPs & \multirow{2}{*}{ Breynia rhamnoides } & 25 & $9.10 \times 10^{-3}$ & \multirow{2}{*}[23]{} \\
\hline & AgNPs & & 64 & $4.00 \times 10^{-3}$ & \\
\hline & AuNPs & \multirow{2}{*}{ Corn-cob } & 35 & $5.80 \times 10^{-3}$ & \multirow{2}{*}[30]{} \\
\hline & AgNPs & & 11 & $5.00 \times 10^{-3}$ & \\
\hline & AuNPs & \multirow{2}{*}{ Codonopsis pilosula root } & 20 & $(2.88 \pm 0.34) \times 10^{-3}$ & \multirow{2}{*}{ This work } \\
\hline & AgNPs & & 10 & $(3.84 \pm 0.32) \times 10^{-3}$ & \\
\hline
\end{tabular}

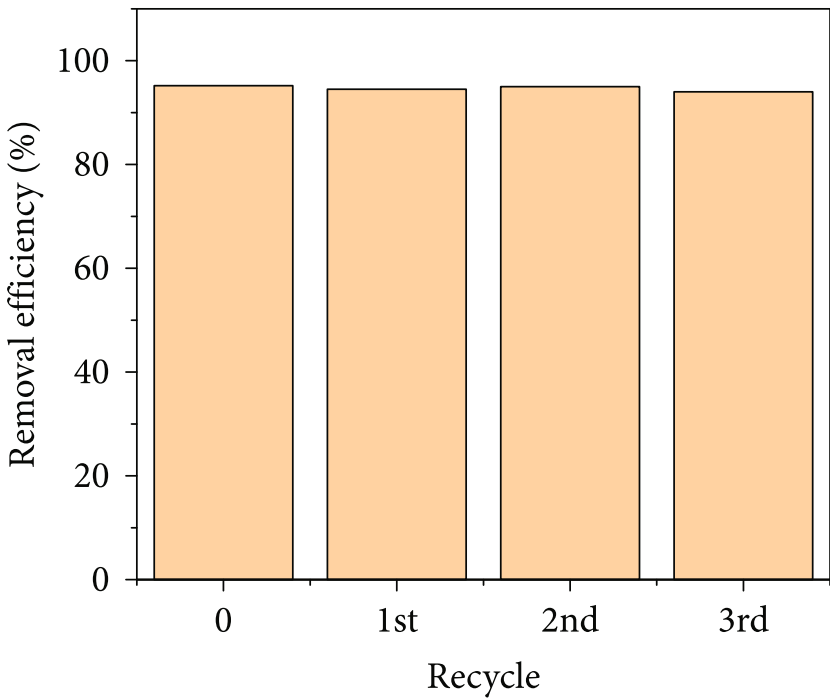

(a)

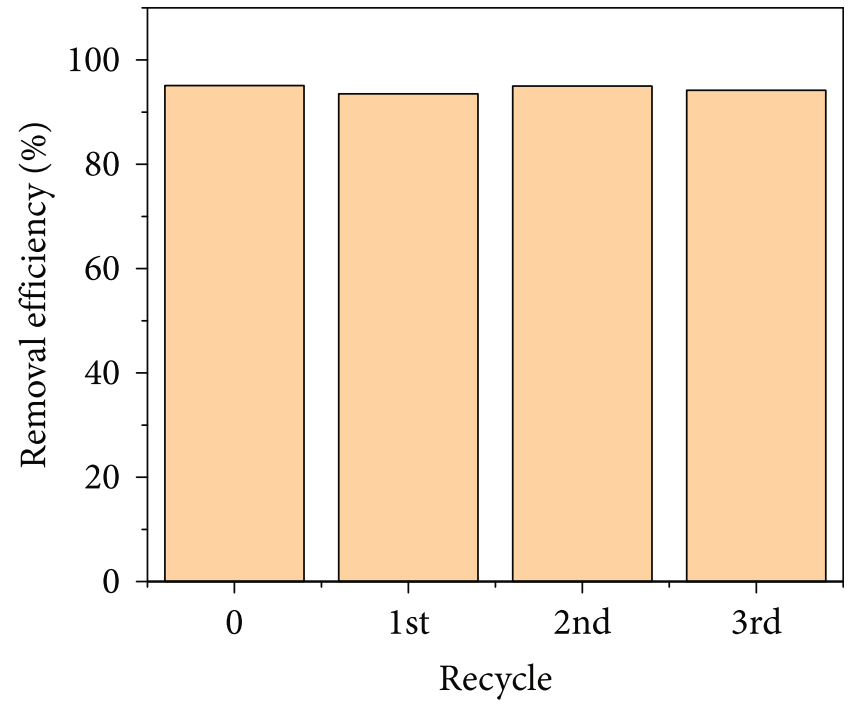

(b)

Figure 12: Reusability of CP-AuNPs (a) and CP-AgNPs (b). 
shape with an average size of about $10-20 \mathrm{~nm}$. The colloidal CP-AgNPs exhibited selective, strong antibacterial activity against three bacterial strains including two Gram-positive B. subtilis and S. aureus, and one Gramnegative $E$. coli, but there was no bacterial activity detected toward Gram-negative S. enteritidis at all tested concentrations. The biogenic MNPs also possessed a high catalytic activity in degradation of 1,4-DNB, 2-NP, 3-NP, and 4NP. Therefore, the novel CP-AgNPs and CP-AuNPs synthesized by the aqueous extract of Codonopsis pilosula roots can be considered as perspective nanomaterials for large-scale biological and catalytic applications.

\section{Data Availability}

The data used to support the findings of this study are included within the article.

\section{Conflicts of Interest}

The authors declare that they have no conflicts of interest.

\section{Acknowledgments}

This research is funded by the Vietnam National Foundation for Science and Technology Development (NAFOSTED) under grant number 104.05-2019.03.

\section{References}

[1] N. K. R. Bogireddy, U. Pal, L. M. Gomez, and V. Agarwal, "Size controlled green synthesis of gold nanoparticles usingCoffea arabicaseed extract and their catalytic performance in 4nitrophenol reduction," RSC Advances, vol. 8, no. 44, pp. 24819-24826, 2018.

[2] K. M. Soto, C. T. Quezada-Cervantes, M. Hernández-Iturriaga, G. Luna-Bárcenas, R. Vazquez-Duhalt, and S. Mendoza, "Fruit peels waste for the green synthesis of silver nanoparticles with antimicrobial activity against foodborne pathogens," $L W T$, vol. 103, pp. 293-300, 2019.

[3] L. K. Ruddaraju, P. N. V. K. Pallela, S. V. N. Pammi, V. S. Padavala, and V. R. M. Kolapalli, "Synergetic antibacterial and anticarcinogenic effects of Annona squamosa leaf extract mediated silver nano particles," Materials Science in Semiconductor Processing, vol. 100, pp. 301-309, 2019.

[4] M. U. Farooq, V. Novosad, E. A. Rozhkova et al., "Gold nanoparticles-enabled efficient dual delivery of anticancer therapeutics to hela cells," Scientific Reports, vol. 8, no. 1, p. $2907,2018$.

[5] S. Lee and B.-H. Jun, "Silver Nanoparticles: Synthesis and application for nanomedicine," International Journal of Molecular Sciences, vol. 20, no. 4, p. 865, 2019.

[6] M. Sengani, A. M. Grumezescu, and V. D. Rajeswari, "Recent trends and methodologies in gold nanoparticle synthesis - A prospective review on drug delivery aspect," OpenNano, vol. 2, pp. 37-46, 2017.

[7] R. D. Nagarajan and A. K. Sundramoorthy, "One-pot electrosynthesis of silver nanorods/graphene nanocomposite using 4sulphocalix[4]arene for selective detection of oxalic acid," Sensors and Actuators B: Chemical, vol. 301, pp. 127132127132, 2019.
[8] A. Taleb, C. Petit, and M. P. Pileni, "Synthesis of highly monodisperse silver nanoparticles from aot reverse micelles: a way to $2 \mathrm{~d}$ and 3d self-organization," Chemistry of Materials, vol. 9, no. 4, pp. 950-959, 1997.

[9] S. V. Banne, M. S. Patil, R. M. Kulkarni, and S. J. Patil, "Synthesis and characterization of silver nano particles for EDM applications," Materials Today: Proceedings, vol. 4, pp. 1205412060, 2017.

[10] G. Lee, "Preparation of silver nanorods through the control of temperature and $\mathrm{pH}$ of reaction medium," Materials Chemistry and Physics, vol. 84, no. 2-3, pp. 197-204, 2004.

[11] Y. M. Yukhin, A. I. Titkov, G. K. Kulmukhamedov, and N. Z. Lyakhov, "Synthesis of silver nanoparticles via reduction of silver carboxylates by ethylene glycol," Theoretical Foundations of Chemical Engineering, vol. 49, no. 4, pp. 490-496, 2015.

[12] R. D. Rivera-Rangel, M. P. González-Muñoz, M. AvilaRodriguez, T. A. Razo-Lazcano, and C. Solans, "Green synthesis of silver nanoparticles in oil-in-water microemulsion and nano-emulsion using geranium leaf aqueous extract as a reducing agent," Colloids and Surfaces A: Physicochemical and Engineering Aspects, vol. 536, pp. 60-67, 2018.

[13] E. Ramya, L. Jyothi, N. S. Gopal, and N. R. Desai, "Optical and biomedical properties of eco-friendly metal nanostructures synthesized using Trigonella foenum-graecum leaf extract," Applied Nanoscience, vol. 8, no. 4, pp. 771-783, 2018.

[14] V. D. Doan, V. T. Le, T. D. Nguyen, T. L. H. Nguyen, and H. T. Nguyen, "Green synthesis of silver nanoparticles usingaganonerion polymorphumleaves extract and evaluation of their antibacterial and catalytic activity," Materials Research Express, vol. 6, no. 11, p. 1150g1, 2019.

[15] K. S. Siddiqi, A. Husen, and R. A. K. Rao, "A review on biosynthesis of silver nanoparticles and their biocidal properties," Journal of Nanobiotechnology, vol. 16, no. 1, p. 14, 2018.

[16] C. Vishwasrao, B. Momin, and L. Ananthanarayan, "Green synthesis of silver nanoparticles using sapota fruit waste and evaluation of their antimicrobial activity," Waste and Biomass Valorization, vol. 10, no. 8, pp. 2353-2363, 2019.

[17] C. Song, F. Ye, S. Liu et al., "Thorough utilization of rice husk: metabolite extracts for silver nanocomposite biosynthesis and residues for silica nanomaterials fabrication," New Journal of Chemistry, vol. 43, no. 23, pp. 9201-9209, 2019.

[18] T. Dodevska, I. Vasileva, P. Denev et al., "Rosa damascena waste mediated synthesis of silver nanoparticles: Characteristics and application for an electrochemical sensing of hydrogen peroxide and vanillin," Materials Chemistry and Physics, vol. 231, pp. 335-343, 2019.

[19] S. S. Hassan, K. Carlson, S. K. Mohanty, Sirajuddin, and A. Canlier, "Ultra-rapid catalytic degradation of 4nitrophenol with ionic liquid recoverable and reusable ibuprofen derived silver nanoparticles," Environmental Pollution, vol. 237, pp. 731-739, 2018.

[20] A. Singhal and A. Gupta, "Efficient utilization of Sal deoiled seed cake (DOC) as reducing agent in synthesis of silver nanoparticles: Application in treatment of dye containing wastewater and harnessing reusability potential for cost-effectiveness," Journal of Molecular Liquids, vol. 268, pp. 691-699, 2018.

[21] B. Mohapatra, D. Kumar, N. Sharma, and S. Mohapatra, "Morphological, plasmonic and enhanced antibacterial properties of Ag nanoparticles prepared using _Zingiber officinale_ extract," Journal of Physics and Chemistry of Solids, vol. 126, pp. 257-266, 2019. 
[22] M. Rafique, I. Sadaf, M. B. Tahir et al., "Novel and facile synthesis of silver nanoparticles using _Albizia procera_ leaf extract for dye degradation and antibacterial applications," Materials Science and Engineering: C, vol. 99, pp. 1313-1324, 2019.

[23] M. Anandan, G. Poorani, P. Boomi et al., "Green synthesis of anisotropic silver nanoparticles from the aqueous leaf extract of _Dodonaea viscosa_ with their antibacterial and anticancer activities," Process Biochemistry, vol. 80, pp. 80-88, 2019.

[24] F. Ameen, P. Srinivasan, T. Selvankumar et al., "Phytosynthesis of silver nanoparticles using _Mangifera indica_flower extract as bioreductant and their broad-spectrum antibacterial activity," Bioorganic Chemistry, vol. 88, p. 102970, 2019.

[25] Y. Jiang, Y. Liu, Q. Guo et al., "Acetylenes and fatty acids from _Codonopsis pilosula_," Acta Pharmaceutica Sinica B, vol. 5, no. 3, pp. 215-222, 2015.

[26] Q.-L. Sun, Y.-X. Li, Y.-S. Cui, S.-L. Jiang, C.-X. Dong, and J. Du, "Structural characterization of three polysaccharides from the roots of _Codonopsis pilosula_ and their immunomodulatory effects on RAW264.7 macrophages," International Journal of Biological Macromolecules, vol. 130, pp. 556-563, 2019.

[27] X. Deng, Y. Fu, S. Luo et al., "Polysaccharide from Radix Codonopsis has beneficial effects on the maintenance of T-cell balance in mice," Biomedicine \& Pharmacotherapy, vol. 112, p. 108682, 2019.

[28] T. M.-T. Nguyen, T. T.-T. Huynh, C.-H. Dang et al., "Novel biogenic silver nanoparticles used for antibacterial effect and catalytic degradation of contaminants," Research on Chemical Intermediates, vol. 46, no. 3, pp. 1975-1990, 2020.

[29] T. T. N. Nguyen, T. T. Vo, B. N. H. Nguyen et al., "Silver and gold nanoparticles biosynthesized by aqueous extract of burdock root, Arctium lappa as antimicrobial agent and catalyst for degradation of pollutants," Environmental Science and Pollution Research, vol. 25, no. 34, pp. 3424734261, 2018.

[30] V.-D. Doan, V.-S. Luc, T. L.-H. Nguyen, T.-D. Nguyen, and T.-D. Nguyen, "Utilizing waste corn-cob in biosynthesis of noble metallic nanoparticles for antibacterial effect and catalytic degradation of contaminants," Environmental Science and Pollution Research, vol. 27, no. 6, pp. 61486162, 2020.

[31] S. Chowdhury, F. Yusof, M. O. Faruck, and N. Sulaiman, "Process optimization of silver nanoparticle synthesis using response surface methodology," Procedia Engineering, vol. 148, pp. 992-999, 2016.

[32] M. A. Garcia, "Surface plasmons in metallic nanoparticles: fundamentals and applications," Journal of Physics D: Applied Physics, vol. 45, no. 38, p. 389501, 2012.

[33] Y. Marcus, "Standard potentials in water and in mixed aqueous organic solvents," in Reference Module in Chemistry, Molecular Sciences and Chemical Engineering, Elsevier, 2018.

[34] A. Gangula, R. Podila, R. M, L. Karanam, C. Janardhana, and A. M. Rao, "Catalytic reduction of 4-nitrophenol using biogenic gold and silver nanoparticles derived from breynia rhamnoides," Langmuir, vol. 27, no. 24, pp. 15268-15274, 2011.

[35] T. T. Vo, C. H. Dang, V. D. Doan, V. S. Dang, and T. D. Nguyen, "Biogenic synthesis of silver and gold nanoparticles from lactuca indica leaf extract and their application in catalytic degradation of toxic compounds," Journal of Inorganic and Organometallic Polymers and Materials, vol. 30, no. 2, pp. 388-399, 2020.

[36] K. Xin Lee, K. Shameli, M. Miyake et al., "Green synthesis of gold nanoparticles using aqueous extract of garcinia mangostana fruit peels," Journal of Nanomaterials, vol. 2016, 7 pages, 2016.

[37] P. Kaithavelikkakath Francis, S. Sivadasan, A. Avarachan, and A. Gopinath, "A novel green synthesis of gold nanoparticles using seaweedLobophora variegataand its potential application in the reduction of nitrophenols," Particulate Science and Technology, vol. 38, no. 3, pp. 365-370, 2020.

[38] L.-C. Lin, T.-H. Tsai, and C.-L. Kuo, "Chemical constituents comparison of Codonopsis tangshen Codonopsis pilosula var. modesta and Codonopsis pilosula," Natural Product Research, vol. 27, no. 19, pp. 1812-1815, 2013.

[39] Y. H. Yang, X. Z. Li, and S. Zhang, "Preparation methods and release kinetics ofLitsea cubebaessential oil microcapsules," RSC Advances, vol. 8, no. 52, pp. 29980-29987, 2018.

[40] J.-Y. He, N. Ma, S. Zhu, K. Komatsu, Z.-Y. Li, and W.-M. Fu, "The genus Codonopsis (Campanulaceae): a review of phytochemistry, bioactivity and quality control," Journal of Natural Medicines, vol. 69, no. 1, pp. 1-21, 2015.

[41] V. Kumar, S. Singh, B. Srivastava, R. Bhadouria, and R. Singh, "Green synthesis of silver nanoparticles using leaf extract of _Holoptelea integrifolia_ and preliminary investigation of its antioxidant, anti- inflammatory, antidiabetic and antibacterial activities," Journal of Environmental Chemical Engineering, vol. 7, no. 3, p. 103094, 2019.

[42] K. S. B. Naidu, N. Murugan, J. K. Adam, and Sershen, "Biogenic synthesis of silver nanoparticles from Avicennia marina seed extract and its antibacterial potential," Bionanoscience, vol. 9, no. 2, pp. 266-273, 2019.

[43] F. Benakashani, A. R. Allafchian, and S. A. H. Jalali, "Biosynthesis of silver nanoparticles using _Capparis spinosa_ L. leaf extract and their antibacterial activity," Karbala International Journal of Modern Science, vol. 2, no. 4, pp. 251-258, 2016.

[44] A. Shahzad, H. Saeed, M. Iqtedar et al., "Size-Controlled Production of Silver Nanoparticles by Aspergillus fumigatus BTCB10: Likely Antibacterial and Cytotoxic Effects," Journal of Nanomaterials, vol. 2019, 14 pages, 2019.

[45] V. Ravichandran, S. Vasanthi, S. Shalini, S. A. A. Shah, M. Tripathy, and N. Paliwal, "Green synthesis, characterization, antibacterial, antioxidant and photocatalytic activity of _Parkia speciosa_ leaves extract mediated silver nanoparticles," Results in Physics, vol. 15, p. 102565, 2019.

[46] S. M. Albukhari, M. Ismail, K. Akhtar, and E. Y. Danish, "Catalytic reduction of nitrophenols and dyes using silver nanoparticles@ cellulose polymer paper for the resolution of waste water treatment challenges," Colloids and Surfaces A: Physicochemical and Engineering Aspects, vol. 577, pp. 548-561, 2019. 